DOI: https://doi.org/10.15517/rce.v36i2.35692

\title{
EL GASTO EN SERVICIOS PÚBLICOS REGULADOS DE LOS HOGARES DE COSTA RICA EN EL AÑO 2013
}

\author{
Gabriel Jesús Villalobos-Rosales ${ }^{1}$
}

Recibido: 06/03/2018

Aprobado: 31/07/2018

\begin{abstract}
RESUMEN
Mediante un análisis descriptivo y de conglomerados (cluster analysis), se estudia el gasto en servicios públicos regulados de los hogares de Costa Rica, cuya regulación recae sobre la Autoridad Reguladora de los Servicios Públicos (Aresep) y la Superintendencia de Telecomunicaciones (Sutel). A partir de la Encuesta Nacional de Ingresos y Gastos 2013 del Instituto Nacional de Estadística y Censos (INEC), se estima un gasto total mensual en servicios públicos regulados de los hogares de 148 mil millones de colones. El comportamiento de este gasto varía, en especial, entre regiones de planificación y nivel de ingreso de los hogares, no así por zona. El impacto de este gasto sobre los ingresos de los hogares es mayor en la zona rural, regiones de planificación periféricas y en los hogares de menores recursos. Usando un análisis de conglomerados -específicamente k-medias-, se identifican cinco grupos de hogares, los cuales se distinguen sobre todo por el gasto mensual que efectúan en transporte público y combustibles.
\end{abstract}

PALABRAS CLAVE: REGULACIÓN, SEGMENTACIÓN, ECONOMÍA.

\section{ABSTRACT}

This paper studies through a descriptive and cluster analysis the expenditure on regulated public services of Costa Rican households, whose regulation corresponds to the Public Services Regulatory Authority (Aresep) and the Superintendence of Telecommunications (Sutel). Based on the 2013 National Survey of Income and Expenses of the National Institute of Statistics and Census (INEC), a total monthly expenditure on regulated public services of households is estimated at 148 milliard colones. The behavior of this expenditure varies mainly between planning regions and income level of households, but not by area (urban and rural). The impact of this expenditure on household income is greater in rural areas, peripheral planning regions and households with fewer resources. Using a cluster analysis, specifically k-means, five groups of households are identified, which are distinguished mainly by the monthly expenditure they make on public transport and fuels.

KEY WORDS: REGULATION, SEGMENTATION, ECONOMY.

1 Autoridad Reguladora de los Servicios Públicos, Dirección General de Atención al Usuario; Código postal 936-1000, San José, Costa Rica, gvillalobosr@gmail.com 


\section{INTRODUCCIÓN}

Los servicios públicos juegan un papel relevante en el desarrollo de las sociedades y en la calidad de vida de los habitantes de una región; se trata de servicios esenciales y necesarios para el quehacer diario de los ciudadanos y el desarrollo de actividades productivas de una nación, por lo que la ausencia de alguno de ellos constituye un elemento perturbador para la sociedad. Servicios como el agua potable, saneamiento, electricidad, infraestructura, comunicaciones, Internet, sistemas de transporte y transporte público son elementos fundamentales para el desarrollo humano de las personas, tanto así que el acceso a estos forman parte de los objetivos y metas universales de la Agenda 2030 para el Desarrollo Sostenible de las Naciones Unidas, adoptada por sus Estados miembros en el año 2015, que tiene entre sus fines erradicar la pobreza y el hambre del mundo, combatir la desigualdad, proteger los derechos humanos y establecer las condiciones para un crecimiento económico sostenible e inclusivo, entre otros (Naciones Unidas, 2015).

De acuerdo con Rozas-Balbontín y Hantke-Domas (2013), en América Latina y el Caribe la conceptualización de los servicios públicos se construyó sobre la base de la legislación española, influenciada por la doctrina francesa de los servicios públicos $y$, en menor medida, por la doctrina italiana. En la doctrina francesa estos servicios se caracterizan por ser actividades a) propias de las funciones del Estado, b) destinadas a satisfacer una necesidad colectiva o de interés general en procura del bien común y c) encauzadas por un régimen jurídico especial. La doctrina española permite distinguir los servicios públicos de otros servicios de interés general, mediante el establecimiento del publicatio, que es un acto legal mediante el cual el Estado asume la titularidad del servicio y excluye su explotación del ámbito privado, salvo concesión o permiso. Para Villar Palasí, citado por Rozas-Balbontín y Hantke-Domas (2013), si una actividad o servicio puede ser libremente prestada por el Estado y los agentes privados (sin mediar concesión), no se considera como servicio público. En Costa Rica, la Procuraduría General de la República (PGR), ante consultas de diferentes órganos del Estado, reiteradamente se ha pronunciado sobre el término del servicio público haciendo énfasis en que es una actividad dirigida a satisfacer el interés general o colectivo, asumida por la Administración Pública mediante el publicatio de la actividad ${ }^{2}$ (PGR, 2000).

En general, el acceso a estos servicios esenciales se realiza a través de una contraprestación económica por parte de los usuarios a las empresas proveedoras, las cuales, debido a la concentración de la oferta que caracteriza estos servicios, disfrutan de un poder de mercado que, sin regulación por parte del Estado (responsable último de estos servicios esenciales), carecerían de incentivos para no sobreponer sus intereses a los de los usuarios. De acuerdo con Solanes (1999), basado en Phillips Jr. (1993), los servicios públicos son actividades en las cuales no siempre hay competencia, por lo cual normalmente están sujetas a regulación por medio de la fijación de tarifas y en las condiciones de servicio, en procura del interés público. En el enfoque económico de los "fallos del mercado", la intervención pública se justifica cuando mediante esta se logra alcanzar una asignación pareto-eficiente ${ }^{3}$ que los mercados no logran alcanzar (Lasheras, 1999).

En Costa Rica, en 1996, mediante la promulgación de la Ley 7593 se crea la Autoridad Reguladora de los Servicios Públicos (Aresep) ${ }^{4}$ como ente encargado de regular estos servicios en el país. Esta ley define servicio público como aquel que "por su importancia para el desarrollo sostenible del país sea calificado como tal por la Asamblea Legislativa, con el fin de sujetarlo a las regulaciones de esta ley" inciso a) del artículo 3. Incluye la electricidad,

2 En el pronunciamiento C-152-2000 la PGR sintetiza las características del servicio público (PGR, 2000).

3 "Una asignación de precios, cantidades y rentas es pareto-eficiente cuando no existe asignación alternativa que, dejando a todos los agentes económicos al menos tan satisfechos como antes, consiga que alguno o algunos estén mejor" (Lasheras, 1999, p. 17). 
acueductos y alcantarillados, suministro de combustible, transporte remunerado de personas y telecomunicaciones (artículo 5).

Con la creación de la Aresep, el Estado costarricense procuraba amortizar los intereses y necesidades tanto de los usuarios como de los prestadores de estos servicios, estableciendo en su ley el principio de servicio al costo, como forma de fijar las tarifas y precios, contemplando únicamente los costos necesarios para brindar el servicio que permitan retribución competitiva y garanticen el adecuado desarrollo de la actividad y la potestad del ente regulador para formular y velar por el cumplimiento de los requisitos de calidad, cantidad, oportunidad y confiabilidad necesarios para la prestación óptima del servicio.

Con la apertura del mercado de las telecomunicaciones en el año 2008, mediante la Ley 8660, Ley de Fortalecimiento y Modernización del Sector Telecomunicaciones de las Entidades Públicas, se modificó parcialmente la Ley 7593 y se creó la Superintendencia de Telecomunicaciones (Sutel) como un ente de desconcentración máxima adscrito a la Aresep, encargado de "regular, aplicar y controlar el ordenamiento jurídico de las telecomunicaciones" artículo 59 Ley 8660. En el artículo 74 de esta ley se declara de interés público "la ampliación, la renovación y la operación de redes públicas de telecomunicaciones", las cuales se utilizan para brindar servicios de telecomunicaciones al público de acuerdo con la Ley 8642, Ley general de telecomunicaciones. En la Sutel, las tarifas se orientan a la competencia y eficiencia de los recursos, mientras que se mantiene la potestad de establecer y garantizar los estándares de calidad de los servicios de telecomunicaciones; así se desprende de las obligaciones y funciones de este ente regulador, establecidas en su ley. En ambos casos, se aprecia la intención del legislador de proteger a los usuarios de estos servicios (interés general), garantizando su acceso sin discriminación por medio de tarifas "justas" y estableciendo niveles de calidad obligatorios para su prestación. Es importante señalar que la rectoría de estos servicios se mantiene en manos del Estado, por medio de sus ministerios u otros entes públicos creados con este fin.

En la presente investigación, se analizan las condiciones de acceso a los servicios públicos regulados por parte de los hogares del país en términos del gasto que las familias realizan para adquirir estos servicios, como reflejo de las implicaciones del sistema de regulación vigente en el país, específicamente del establecimiento de los precios y tarifas reguladas según los principios mencionados. Se desea determinar si el patrón de gasto en servicios públicos y su impacto sobre el ingreso del hogar presenta variaciones relevantes por ubicación geográfica y la condición económica de los hogares, especialmente en aquellos de menores recursos, y si el gasto en servicios públicos define o segmenta los hogares del país de acuerdo con los servicios públicos que estos consumen.

En Costa Rica, existen pocos análisis sobre el gasto en servicios públicos de los hogares del país. Para el 2017, el Programa Estado de Nación (PEN) -como propuesta innovadora en su informe anualanalizó de forma exploratoria la equidad en los servicios públicos ${ }^{5}$. Para esto, utilizó la Encuesta Nacional de Ingresos y Gastos 2013 del INEC y estimó la proporción del ingreso que los hogares destinan a estos servicios, encontrando que esta proporción varió de 5,5\% a nivel nacional, a 6,4\% en la zona rural, a 7,5\% en la región Pacífico Central y a cerca del 12\% en los hogares de menores ingresos. Además, identificaron que a medida que disminuye el ingreso de los hogares, aumenta el peso de los servicios públicos sobre sus ingresos. La investigación se profundizó mediante un análisis de conglomerados, con el cual se determinaron tres grupos de hogares (PEN, 2017).

Amarante y Ferrando (2011) analizaron el perfil de los hogares en relación con el acceso y gasto en servicios como el agua y la electricidad para Uruguay, con el fin de avanzar en el diseño

No se detalla los servicios que se incluyen en esta variable. 
de una política pública que facilitara su acceso a las poblaciones más vulnerables. Utilizando la Encuesta Nacional de Gastos e Ingresos de los hogares del 2006 de ese país, encontraron altos porcentajes de hogares que acceden a estos servicios, con variaciones sustanciales por región (entre 82,7 y $99,7 \%$ en electricidad, entre 22,7 y $99,1 \%$ en agua por red general) y por niveles de ingreso (entre 70,3 y 98,7\% en electricidad y entre 83,8 y 95,5\% en agua por red general). Sobre la composición del gasto en servicios del hogar ${ }^{6}$, los autores determinaron que el servicio de electricidad concentró cerca del $60 \%$ de ese gasto, el agua poco menos del $20 \%$ y el supergás presentó una participación importante (mayor al 10\%), comportamiento que varió por región y por niveles de ingreso. En relación con los ingresos del hogar, estos autores identificaron que los hogares de menores ingresos destinaron $11,1 \%$ de sus ingresos a estos servicios ${ }^{7}$, mientras aquellos con mayores ingresos únicamente utilizaron 3,5\%, patrón que se mantuvo en los servicios electricidad y agua de forma individual. En un análisis sobre la equidad de las tarifas de los servicios públicos domiciliarios y su impacto en la capacidad de pago para la ciudad de Bogotá (Colombia) realizado por el Centro de Investigaciones para el Desarrollo (CIP) de la Universidad Nacional de Colombia, en el 2004, se estimó que el gasto de los hogares en estos servicios domiciliarios ${ }^{8}$ llegó a representar $11 \%$ del ingreso de hogares de menores recursos, mientras aquellos de mayores recursos destinaron 7\%, situación preocupante por tratarse de servicios básicos (CIP, 2004).

\section{METODOLOGÍA}

En este apartado, se detallan los datos utilizados, el tratamiento a la variable de gastos de los hogares por parte del INEC, el procedimiento utilizado para la construcción de las variables de gasto en servicios públicos y la técnica empleada para segmentar los hogares de acuerdo con su gasto en los distintos servicios públicos disponibles. El análisis de conglomerados, conocido como cluster analysis (en inglés), se efectuó con el programa estadístico R (versión 3.4.2) y el resto de los procesamientos se realizaron con el programa estadístico SPSS (versión 20).

Para la presente investigación, se trabajó con los archivos de datos de la Encuesta Nacional de Ingresos y Gastos 2013 (ENIGH 2013) efectuada por el INEC, durante el periodo de octubre 2012 y octubre de 2013 (INEC, 2014). Esta encuesta, además de tener entre sus objetivos específicos conocer la estructura de ingreso de los hogares, pretende determinar la estructura de gasto de los hogares de Costa Rica. La ENIGH 2013 se realizó a nivel nacional, se estratificó por zona (urbana y rural) y regiones de planificación del país y la información se recabó de los miembros residentes habituales de hogares del país (se excluye viviendas colectivas) en el periodo señalado. El diseño muestral para seleccionar las viviendas fue probabilístico de áreas, estratificado, bietápico y replicado; se utilizó el marco muestral de viviendas construido por el INEC a partir de los Censos Nacionales de Vivienda y Población del 2011. El tamaño de muestra seleccionado fue de 7020 viviendas, obteniéndose un tamaño de muestra efectivo de 5075. Los resultados de la encuesta son representativos a nivel nacional, por zona y por regiones de planificación.

\footnotetext{
6 "Incluye los servicios energía eléctrica, agua, supergás, leña, gas por cañería, alcohol, fueloil, queroseno y carbón.

$7 \quad$ En este caso únicamente incluye los servicios de electricidad, supergás, leña y agua.

8 Incluye los servicios acueductos, alcantarillados, aseo, energía, teléfono.
} 


\section{Variable de gasto de los hogares en la ENIGH 2013}

La ENIGH 2013 tiene entre sus objetivos conocer los patrones de gasto de los hogares, para esto el INEC trata los gastos de la forma que se detalla a continuación (INEC, 2014).

i. Se define el gasto total de los hogares como "el valor de los bienes y servicios adquiridos en el mercado, recibidos gratuitamente o producidos por los hogares para satisfacer las necesidades $y$ deseos de sus miembros o para otros pagos obligatorios".

ii. El gasto total de los hogares se divide en dos grupos: el gasto corriente y transacciones de capital, y dentro de estos se identifican otros subgrupos de gastos.

iii. El gasto corriente está compuesto por gastos de consumo y transferencias corrientes. Los primeros corresponden a los gastos del hogar destinados a satisfacer las necesidades y preferencias del hogar y sus miembros; mientras que las transferencias corrientes abarcan el pago de impuestos, seguros, pensiones, donaciones y otras transferencias voluntarias. Estos gastos se caracterizan por ser de frecuencia regular.

iv. El gasto de consumo se imputa al valor monetario de los bienes y servicios de consumo adquiridos por el hogar y al valor monetario estimado de las transacciones no monetarias como trueque, ingresos en especie, autoconsumo, autosuministro y donaciones, ambos casos a precios del mercado. Los bienes y servicios adquiridos por el hogar para ser donados no se consideran como gastos de consumo, sino como transferencia en especie.

v. El gasto de consumo de los hogares es un agregado de los grupos de gasto definidos por la Clasificación del Consumo Individual por Finalidades (CCIF) de la Organización de Naciones Unidas (ONU), de la cual el INEC utiliza los 12 grupos correspondientes a los hogares.

\section{Construcción de variables de gasto en servicios públicos de los hogares}

A partir de la información disponible en la ENIGH 2013 y considerando los servicios públicos regulados por la Aresep y la Sutel, que pueden ser consumidos por el hogar o por sus miembros fuera de este, se construyó una variable de gasto de consumo para cada uno de los siguientes servicios: acueductos y alcantarillados (acueductos), electricidad, gas para cocinar, combustibles ${ }^{9}$, transporte público (transporte), televisión por suscripción ${ }^{10}$, telefonía fija, Internet fijo, telefonía e Internet móvil, otros servicios (incluye los servicios de revisión técnica vehicular ${ }^{11}$, peajes ${ }^{12}$ y otros gastos por la instalación de servicios públicos regulados). Además, se construyó una variable adicional que se compone de la suma de todos los anteriores y constituye el gasto total de los hogares en servicios públicos. El procedimiento utilizado para construir estas variables fue el siguiente:

$9 \quad$ En el caso de los servicios denominados servicios de gas para cocinar y servicio de combustibles, se hace referencia al servicio público de suministro de combustibles derivados del hidrocarburos destinados al consumidor final de conformidad a lo establecido en el inciso d) artículo 5 de la Ley 7593.

10 Catalogado como servicio de telecomunicaciones disponible al público por la Sutel, Sutel (2014).

11 De acuerdo con la Ley 9078, Ley de Tránsito por Vías Públicas Terrestres y Seguridad Vial.

12 De conformidad con la Ley 7798, Ley de Creación del Consejo de Vialidad. 
i. Con base en el Manual de códigos de artículos de la ENIGH 2013, que incluye más de 5000 bienes y servicios, se identificaron los códigos de los artículos de consumo del hogar que correspondían a algún servicio público regulado. En el Anexo 1 se detalla los códigos y la descripción de los artículos utilizados para construir las variables de gastos en cada uno de los servicios. En total, se utilizaron 45 artículos.

ii. Con el archivo de datos de Gastos de la ENIGH 2013, para cada uno de los 45 artículos identificados, se creó una variable de gasto, a la cual se le asignó el valor de la variable "GASTO MES" del archivo de datos correspondiente a cada uno de los artículos.

iii. Posteriormente, para crear la variable de gasto en cada uno de los servcios públicos indicados anteriormente, se sumó el gasto de los artículos que formaban cada servicio público. La variable de gasto total en servicios públicos se creó de la suma de estas últimas.

iv. Para cada uno de los servicios, las variables de gasto se sumaron por hogar, para obtener el gasto de los hogares en cada uno de los servicios.

Los gastos de hogares se recaban entre octubre de 2012 y octubre de 2013, por lo cual se consideran como promedios a abril 2013. En el archivo de datos de Gastos, la información es mensual, por lo que se trabajara con esta periodicidad. En relación con los artículos seleccionados, para crear las variables de gasto en cada servicio público regulado, es importante indicar que estos se recopilan independientemente de si los adquieren de un prestador autorizado del servicio o no; como en el caso del transporte, en el cual se incluye los gastos que los hogares indicaron realizar en el artículo 1540, Transporte regular colectivo (taxis o carros privados y taxi pirata), que podría abarcar el uso de un transporte no autorizado, de igual forma se incorporan los gastos en servicios públicos regulados, pero que son prestados por instituciones no reguladas por la Aresep o Sutel, como es el caso del servicio de acueductos y alcantarillados que brindan las municipalidades ${ }^{13}$. Se toma esta decisión porque se pretende conocer el gasto de los hogares en estos servicios públicos que han sido normados para ser regulados por la Aresep y Sutel, más allá de si en algunos casos parte de estos servicios son brindados por prestadores no autorizados o no regulados por la Aresep y la Sutel.

\section{Análisis de conglomerados}

Para segmentar los hogares del país de acuerdo con el gasto que realizan en los servicios públicos definidos en la presente investigación (acueductos y alcantarillados, electricidad, gas para cocinar, combustibles, transporte, televisión por suscripción, telefonía fija, Internet fijo, telefonía e Internet móvil y otros servicios), se efectúa un análisis de conglomerados, que es una técnica multivariada que permite dividir o particionar un conjunto de datos en grupos o subconjuntos de conformidad con los valores que estos presenten en las variables seleccionadas para el análisis. Esta técnica busca que los objetos u observaciones dentro de cada grupo sean lo más similares entre sí, pero lo más diferentes a los objetos u observaciones dentro de los otros grupos (Han, Kamber y Pei, 2012). El análisis de conglomerados puede generar distintos resultados para un mismo conjunto de datos, dependiendo de los procedimientos utilizados, especialmente por la técnica de agrupación y medida de proximidad o distancia seleccionada. Este tipo de análisis suele divirse en métodos de partición y métodos jerárquicos, aunque existen otras técnicas de agrupación, como el método basado en la densidad de los datos (Density-based) o en la estructura de los datos (Grid-based), entre otros (Han et al, 2012). 
En esta investigación se trabaja con el método de partición denominado k-medias. En esta técnica, el conjunto de datos (D) se divide en un número determinado de k-grupos (G_1...G_k), con el objetivo de que la variabilidad dentro de los grupos sea la menor posible y la variabilidad entre los grupos sea la mayor posible. En términos generales, establece para cada grupo $\left(\mathrm{G}_{-} \mathrm{i}\right)$ un valor representativo conocido como centroide (c_i ), el cual corresponde al valor medio de todos los objetos dentro del grupo (G_i ). De esta forma, cada objeto (o) del conjunto de datos (D) se asigna al grupo $\left(\mathrm{G} \_\mathrm{i}\right.$ ), de manera que la distancia entre el valor del centroide (c_i ) y el objeto (o) sea la menor. Para medir esta distancia, se utiliza la distancia euclidiana (Han et al, 2012). De esta forma, el objetivo de minimizar la variación dentro de los grupos (within-cluster variation) se convierte en un ejercicio de minimización de la suma del error al cuadrado (SSE), definida como la suma al cuadrado de la distancia entre los objetos de un grupo y su centroide (Kaufman y Rousseeuw, 1990) ${ }^{14}$.

Los resultados del análisis de k-medias pueden ser sensibles a los valores iniciales que se establecen aleatoriamente para crear los grupos. Por este motivo, se recomienda efectuar el procedimiento en varias ocasiones. En esta investigación, el análisis de conglomerados se realizó en el programa estadístico R, el cual permite establecer un número determinado de inicios aleatorios para calcular los grupos y devuelve la solución que minimiza la variabilidad dentro de los grupos en la mayoría de los casos. No existe un procedimiento de análisis de conglomerados único o predominante, tampoco existe un método mejor que otro, por lo que todo va a depender del objeto de estudio y los objetivos de la investigación. No obstante, el análisis de conglomerados permite utilizar indicadores para evaluar la calidad de los grupos creados, los datos que se utilizan en el análisis, así como indicadores para seleccionar el número óptimo de subconjuntos. En este estudio, se utiliza el estadístico de Hopkins, para determinar si el conjunto de datos presenta una estructura aleatoria o no, el método del codo para identificar el número óptimo de grupos $(\mathrm{k})$ que es una representación gráfica de la variancia dentro de las agrupaciones (within-cluster variation) y el coeficiente de silueta, para evaluar la calidad de los grupos, indica qué tan compactos y separados están los subconjuntos (Han et al, 2012).

14 La suma total del error al cuadro del análisis de conglomerados se define como:

$$
\begin{aligned}
& S S E=\sum_{i=1}^{k} \operatorname{SSE}\left(G_{i}\right) \\
& \operatorname{SSE}\left(G_{i}\right)=\sum_{o \in G_{i}} \operatorname{dist}\left(\boldsymbol{o}, c_{i}\right) \\
& c_{i}=\frac{1}{n_{i}} \sum_{o \in G_{i}} o
\end{aligned}
$$

Donde n_i corresponde al tamaño del grupo $i\left(G_{i}\right)$ 


\section{RESULTADOS}

Para el año 2013, se estimó un gasto total mensual en servicios públicos regulados por parte de los hogares de Costa Rica de 148 mil millones de colones mensuales (cuadro 1), para un total anual de alrededor de 1,8 billones de colones, cifra que representa 7,2\% del Producto Interno Bruto (PIB) del país de ese año.

A nivel nacional, cerca de una cuarta parte de ese gasto mensual se destina al servicio de combustible, alrededor del 18\% se destina a transporte público y electricidad, respectivamente, y cerca del $15 \%$ al de telefonía e Internet móvil; estos 4 servicios en conjunto abarcan poco más del $75 \%$ del gasto total mensual en servicios públicos. Otros servicios con una participación mayor al 5\%, son el servicio de televisión por suscripción, con poco menos del 8\% y el servicio de acueductos y alcantarillados, con cerca del $7 \%$ del gasto total mensual de los hogares en servicios públicos regulados ${ }^{15}$.

En términos de los hogares que efectúan gastos en estos servicios, aquellos con mayor incidencia son electricidad (99\% de los hogares), acueductos (93\%) y telefonía e Internet móvil (77\%); los servicios de transporte, televisión por suscripción y telefonía fija agrupan poco más de 50\% de los hogares cada uno, mientras que el gas para cocinar, combustibles e Internet fijo presentan menos incidencia (43, 32 y $24 \%$ de los hogares del país, respectivamente).

CUADRO 1

COSTA RICA: GASTO TOTAL MENSUAL EN SERVICIOS PÚBLICOS REGULADOS DE LOS HOGARES Y SU INCIDENCIA EN ESTOS. AÑO 2013

\begin{tabular}{lrrrr}
\hline \multirow{2}{*}{ Servicio } & \multicolumn{2}{c}{ Gasto } & \multicolumn{2}{c}{$\begin{array}{c}\text { Hogares que los } \\
\text { adquieren } \\
\text { (Porcentaje) }\end{array}$} \\
\cline { 2 - 3 } Servicios públicos & $\begin{array}{c}\text { Total } \\
\text { (Millones de colones) }\end{array}$ & Porcentaje & 100 \\
Combustibles & $148.179,8$ & 100 & 32,2 \\
Transporte público & $36.379,9$ & 24,6 & 58,5 \\
Electricidad & $27.641,6$ & 18,7 & 99,2 \\
Telefonía e Internet móvil & $26.063,6$ & 17,6 & 77,5 \\
Televisión por suscripción & $21.699,5$ & 14,6 & 55,9 \\
Acueductos y alcantarillado & $11.548,3$ & 7,8 & 93,6 \\
Telefonía fija & $9.950,3$ & 6,7 & 52,0 \\
Internet fijo & $6.248,6$ & 4,2 & 24,1 \\
Gas para cocinar & $3.850,9$ & 2,6 & 42,7 \\
Otros servicios & $3.679,9$ & 2,5 & 38,6 \\
\hline
\end{tabular}

Fuente: Elaboración propia con datos de la ENIGH 2013 del INEC.

15 En el anexo 6 se compara el gasto mensual total de los hogares de Costa Rica con el ingreso mensual promedio de las empresas proveedoras del servicio de electricidad y acueductos y alcantarillados por concepto de tarifa residencial, no se observan diferencias significativas con un nivel de confianza del 95\% entre ambos datos. Los datos de las empresas proveedoras se obtienen de la página web de la Aresep www.aresep.go.cr y consultas realizadas en este ente. 


\section{Composición y distribución del gasto en servicios públicos regulados por zona y región ${ }^{16}$}

La distribución del gasto en servicios públicos regulados entre los distintos servicios no muestra mayor variación por zona de residencia. Como se observa en el cuadro 2 , los servicios que presentan diferencias significativas entre una zona y otra son televisión por suscripción $(8,5 \%$ del gasto en servicios públicos en la zona urbana y $5 \%$ en la rural), Internet fijo ( $3 \%$ en la zona urbana menos del $1 \%$ en la rural) y gas para cocinar (2\% en la zona urbana y $4,4 \%$ en la rural). Donde se aprecia una distinción relevante es en la media del gasto mensual en servicios públicos de los hogares por zona, ya que mientras en el área urbana se destina en promedio 116 mil colones, en la rural es de poco más de 78 mil colones. Es importante observar que, aunque el monto que destinan los residentes de zona rural es menor al de los de la urbana, en términos de ingresos del hogar, los hogares rurales en promedio destinan $16,7 \%$ de sus ingresos a la adquisición de servicios públicos regulados, mientras que los urbanos en promedio ocupan $12,8 \%$.

La distribución del gasto en servicios públicos presenta mayores variaciones entre las regiones de planificación del país, principalmente entre la región Central y las regiones periféricas. En el caso del combustible, abarca $26 \%$ del gasto total mensual en la región Central, mientras que no llega a representar el 20\% del gasto en las regiones Pacífico Central y Huetar Caribe. El servicio de electricidad, que ocupa el 16,6\% del gasto en servicios públicos de los hogares de la región Central, concentra poco más del 20\% en las regiones Chorotega, Pacífico Central y Huetar Norte. La televisión por suscripción que alcanza alrededor del 8,4\% en la región Central y Chorotega, cae a cerca del 5,6\% en la región Brunca y en la Huetar Norte. El de acueductos y alcantarillados que abarca poco más del 8\% en las regiones Chorotega y Pacífico Central, ocupa 5,3\% del gasto en la región Huetar Norte y el servicio de gas para cocinar que representa 1,7\% del gasto en la región Central, concentra entre el 3,3 y 5,5\% del gasto de los hogares en el resto de las regiones de planificación. Los servicios de transporte y telefonía e Internet móvil presentan una proporción similar del gasto en servicios públicos en todas las regiones de planificación.

También se observan distinciones relevantes en relación con la media del gasto en servicios públicos de los hogares entre las distintas regiones de planificación. Mientras las regiones Brunca, Huetar Caribe y Huetar Norte presentan un gasto medio en servicios públicos de alrededor de 80 mil colones mensuales, los de la región Central destinan 118 mil colones. Sin embargo, los hogares de esta región únicamente emplean el 12,7\% de sus ingresos mensuales en adquirir estos servicios, mientras que las regiones Chorotega y Pacífico Central, son las que mayor proporción de sus ingresos mensuales destinan a estos servicios, alrededor del $16 \%$.

No todos los hogares del país consumen todos los servicios públicos regulados. De hecho, existen servicios que pueden ser sustitutos, como el combustible, el transporte público, además de la telefonía e Internet móvil y los servicios de telefonía fija e Internet fijo. Como se observa en el cuadro 2, cerca del $100 \%$ de los hogares adquirieron algún servicio público en el periodo de la encuesta, tanto a nivel nacional como por zona y región de residencia. Los servicios de electricidad, acueductos y telefonía e Internet móvil presentan una alta incidencia (superior al 75\% a nivel nacional). En el caso de acueductos, se aprecian variaciones considerables (mayores a 10 puntos porcentuales), tanto por zonas como por regiones de planificación. El transporte, televisión por suscripción y telefonía fija son adquiridos por más del 52\% de los hogares del país. Estos dos últimos servicios presentan diferencias sustanciales entre zonas y regiones de planificación.

$\overline{16 \quad \text { Los }}$ datos que se exponen y se comparan entre zonas y regiones de planificación muestran diferencias significativas con un nivel de confianza del 95\%. En los anexos 2, 3 y 5 se detalla el intervalo de confianza para todas las estimaciones realizadas con un nivel de confianza del 95\%. 
En el caso de la televisión por suscripción en la zona rural, únicamente lo adquiere alrededor del 30\% de los hogares, mientras en la zona urbana llega al 65,5\%, y por regiones, en las regiones Brunca, Huetar Caribe y Huetar Norte cerca del $40 \%$ de los hogares lo consumen versus el 63,5\% de la región Central. En el caso del servicio de telefonía fija, el 56,7\% de los hogares de la zona urbana realizan gasto en este servicio y en la zona rural esta cifra llega al 39\%. Por regiones, este servicio está presente en el $61 \%$ de los hogares de la región Central y llega alrededor del $40 \%$ en las otras regiones. Este patrón se repite con el Internet fijo, el cual es utilizado en $24 \%$ de los hogares a nivel nacional, pero solo en cerca del 7,5\% de los hogares de la zona rural (versus el $30 \%$ en la zona urbana) y alrededor del $11 \%$ en las regiones periféricas (versus el $32 \%$ de la Central). Destaca el caso del gas para cocinar, debido a su menor incidencia en la zona urbana y la región Central: en la zona urbana está presente solo en 39\% hogares, mientras en la zona rural llega a 54,3\%; por regiones, el 33\% de los hogares de la región Central lo consumen, cifra que llega alrededor del 60\% en el resto de las regiones (con excepción de la Chorotega). 


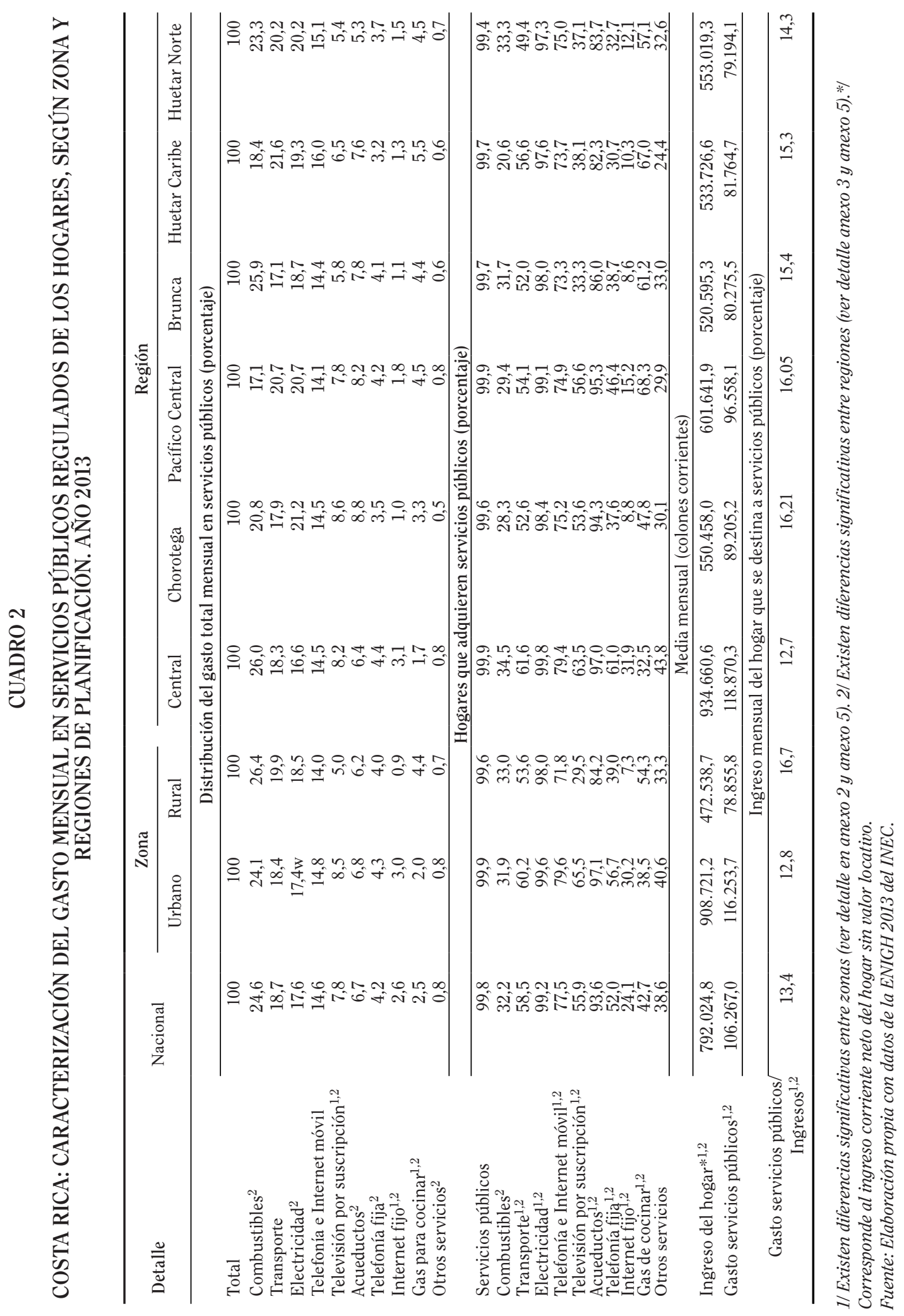


Composición y distribución del gasto en servicios públicos regulados por niveles de ingreso ${ }^{17}$

El gasto total mensual en servicios públicos regulados de los hogares del país muestran una composición distinta a diferentes niveles de ingresos. Como se observa en el cuadro 3, los hogares con mayores ingresos, pertenecientes al cuarto y quinto quintil de ingreso, con una media de ingresos por hogar de 821 mil y 2 millones de colones, respectivamente, presentan el combustible como principal rubro de gasto en servicios públicos regulados, el cual ocupa el 26 y 36\% de este gasto en estos hogares. Por el contrario, en los hogares de menores ingresos, que pertenecen al primer quintil de ingresos del país, donde la media de ingreso por hogar es de 225 mil colones, el principal rubro de gasto en servicios públicos regulados corresponde a electricidad, el cual abarca poco más del 25\% de este gasto. En los hogares con ingresos medios, pertenecientes al segundo y tercer quintil de ingresos, con una media de ingresos por hogar de 376 mil y 550 mil colones, el principal componente del gasto en servicios públicos recae sobre el servicio de transporte, el cual concentra el 25\% de ese gasto en cada caso. De hecho, estos tres servicios presentan diferencias sustanciales (mayores a 10 puntos porcentuales) entre distintos niveles de ingreso, mientras que la telefonía fija es el único servicio que no presenta diferencia significativa.

La media del gasto en servicios públicos regulados por hogar muestra diferencias relevantes por nivel de ingreso, los hogares de mayores recursos (quinto quintil) gastan en promedio 3,4 veces el gasto de los hogares de menores recursos (primer quintil) en servicios públicos. En términos relativos, estos últimos destinan una proporción sustancialmente mayor de sus ingresos al consumo de servicios públicos, de una cuarta parte, mientras que los hogares más acomodados ocupan el 9,5\%.

Los servicios públicos regulados que los hogares de Costa Rica adquieren reflejan cierta relación con su nivel de ingreso. Como se detalla en el cuadro 3, para telefonía e Internet móvil, televisión por suscripción, telefonía fija, combustible e Internet fijo, la proporción de hogares que adquieren estos servicios aumenta conforme aumenta el nivel de ingreso, observándose diferencias superiores a los 45 puntos porcentuales para los cuatro últimos servicios. En el caso de los servicios de transporte y gas para cocinar este patrón no se aprecia, pues la proporción de hogares que gasta en estos servicios crece de los niveles de ingreso bajo (primer quintil) a los niveles medio (segundo y tercer quintil) $y$ disminuyen en los niveles de ingreso alto (quinto quintil), con diferencias relevantes (cercanas a los 20 puntos porcentuales). Esto hace suponer que estos servicios son sustituidos por otros como el combustible y la electricidad. La electricidad $y$ acueductos tienen mayor incidencia en los hogares, pues la mayoría de los hogares los adquieren (alrededor del 99 y 92\% en cada nivel de ingreso), con excepción del primer quintil para el servicio de acueductos.

17 Los datos que se exponen y se comparan entre niveles de ingreso (quintiles) muestran diferencias significativas entre ellas con un nivel de confianza del 95\%. En los anexos 4 y 5 se detalla el intervalo de confianza para todas las estimaciones realizadas con un nivel de confianza del 95\%. 
CUADRO 3

COSTA RICA: CARACTERIZACIÓN DEL GASTO MENSUAL EN SERVICIOS PÚBLICOS REGULADOS DE LOS HOGARES, SEGÚN NIVEL DE INGRESO. AÑO 2013

\begin{tabular}{|c|c|c|c|c|c|}
\hline \multirow{2}{*}{ Detalle } & \multicolumn{5}{|c|}{ Nivel de ingreso (quintil) } \\
\hline & II & III & IV & & $\mathrm{V}$ \\
\hline & \multicolumn{5}{|c|}{ Distribución del gasto total mensual en servicios públicos (porcentaje) } \\
\hline Total & 100 & 100 & 100 & 100 & 100 \\
\hline Combustibles $^{1}$ & 11,1 & 13,0 & 16,1 & 26,3 & 36,2 \\
\hline Transporte $^{1}$ & 23,0 & 25,3 & 25,4 & 18,4 & 11,5 \\
\hline Electricidad ${ }^{1}$ & 26,6 & 20,9 & 18,3 & 16,2 & 14,1 \\
\hline Telefonía e Internet móvil ${ }^{1}$ & 12,6 & 14,6 & 14,4 & 14,7 & 15,4 \\
\hline Televisión por suscripción ${ }^{1}$ & 6,4 & 7,3 & 7,9 & 8,3 & 8,1 \\
\hline Acueductos $^{1}$ & 10,1 & 8,6 & 7,8 & 6,1 & 4,9 \\
\hline Telefonía fija & 3,6 & 4,1 & 4,3 & 4,4 & 4,3 \\
\hline Internet fijo ${ }^{1}$ & 0,9 & 1,3 & 2,0 & 2,9 & 3,7 \\
\hline Gas para cocinar ${ }^{1}$ & 5,3 & 4,3 & 3,2 & 2,0 & 0,9 \\
\hline \multirow{2}{*}{ Otros servicios $^{1}$} & 0,5 & 0,7 & 0,6 & 0,7 & 0,9 \\
\hline & \multicolumn{5}{|c|}{ Hogares que adquieren servicios públicos (porcentaje) } \\
\hline Servicios públicos & 99,7 & 99,8 & 99,7 & 100,0 & 100,0 \\
\hline Electricidad $^{1}$ & 98,0 & 99,0 & 99,4 & 99,6 & 99,9 \\
\hline Acueductos ${ }^{1}$ & 86,8 & 93,7 & 94,8 & 95,2 & 97,5 \\
\hline Telefonía e Internet móvil ${ }^{1}$ & 64,8 & 71,6 & 78,3 & 81,9 & 91,0 \\
\hline Transporte $^{1}$ & 54,3 & 61,2 & 65,5 & 63,9 & 47,3 \\
\hline Televisión por suscripción ${ }^{1}$ & 29,5 & 41,6 & 54,9 & 67,9 & 85,5 \\
\hline Telefonía fija ${ }^{1}$ & 29,0 & 40,9 & 53,2 & 61,5 & 75,2 \\
\hline Gas para cocinar ${ }^{1}$ & 46,0 & 50,8 & 48,5 & 41,1 & 27,2 \\
\hline Combustibles $^{1}$ & 14,3 & 21,0 & 26,5 & 40,1 & 58,9 \\
\hline Internet fijo ${ }^{1}$ & 5,2 & 10,9 & 19,4 & 30,9 & 54,1 \\
\hline \multirow{2}{*}{ Otros servicios ${ }^{1}$} & 17,4 & 25,8 & 30,1 & 48,4 & 71,5 \\
\hline & \multicolumn{5}{|c|}{ Media mensual (colones corrientes) } \\
\hline \multirow{3}{*}{$\begin{array}{l}\text { Ingreso del hogar*1 } \\
\text { Gasto servicios públicos del } \\
\text { hogar }^{1}\end{array}$} & $225.615,4$ & $376.506,7$ & $550.096,5$ & $821.011,0$ & $1.987 .355,2$ \\
\hline & $55.559,9$ & $75.328,8$ & $93.862,8$ & $117.903,7$ & $188.449,1$ \\
\hline & \multicolumn{5}{|c|}{ Ingreso mensual del hogar que se destina a servicios públicos (porcentaje) } \\
\hline $\begin{array}{l}\text { Gasto servicios públicos/ } \\
\text { Ingresos }^{1}\end{array}$ & 24,6 & 20,0 & 17,1 & 14,4 & 9,5 \\
\hline
\end{tabular}

1/ Existen diferencias significativas entre niveles de ingreso con un nivel de confianza del 95\% (ver detalle en anexo $4 y$ anexo 5).

*/ Corresponde al ingreso corriente neto del hogar sin valor locativo.

Fuente: Elaboración propia con datos de la ENIGH 2013 del INEC.

El gasto total mensual en servicios públicos regulados de los hogares de Costa Rica por niveles de ingreso, tomando en cuenta los hogares que efectivamente realizaron gastos en estos servicios, permite calcular cuánto destina en promedio cada hogar al servicio público regulado que consume, así como el peso de cada uno sobre la media de ingresos de esos hogares. Estos resultados muestran que, en todos los servicios públicos regulados (con excepción del gas para cocinar), los hogares de mayores ingresos (quinto quintil) presentan el gasto medio más alto; mientras que 
aquellos con menores ingresos (primer quintil), el más bajo. La diferencia en el gasto entre estos dos grupos se acentúa en los servicios de telefonía e Internet móvil, combustibles y transporte, donde los hogares más adinerados invierten 3,0, 2,7 y 2,0 veces lo que gastan hogares menos acomodados (10.726 colones, 42.973 colones y 23.441 colones) respectivamente (cuadro 4). No obstante, como se observa en el gráfico 1, en relación con el ingreso de los hogares, los primeros destinan una proporción sustancialmente menor de sus ingresos versus los hogares de menores ingresos.

\section{CUADRO 4 \\ COSTA RICA: GASTO MENSUAL MEDIO EN SERVICIOS PÚBLICOS REGULADOS DE LOS HOGARES, SEGÚN NIVEL DE INGRESO. AÑO 2013. (CIFRAS EN COLONES CORRIENTES)}

\begin{tabular}{lrrrrrr}
\hline \multirow{2}{*}{ Servicios* $^{*}$} & \multirow{5}{*}{ Nacionales } & \multicolumn{5}{c}{ Nivel de ingreso (quintil) } \\
\cline { 3 - 7 } & 106.267 & 55.560 & 75.329 & 93.863 & 117.904 & 188.449 \\
\hline Servicios públicos $^{1}$ & 80.937 & 42.973 & 46.305 & 56.803 & 77.423 & 115.787 \\
Combustibles $^{1}$ & 33.853 & 23.441 & 31.109 & 36.279 & 33.939 & 45.875 \\
Transporte $^{1}$ & 18.819 & 15.047 & 15.888 & 17.255 & 19.208 & 26.600 \\
Electricidad $^{1}$ & 20.040 & 10.726 & 15.336 & 17.201 & 21.127 & 31.848 \\
Telefonía e Internet móvil $^{1}$ & 14.798 & 11.911 & 13.161 & 13.446 & 14.383 & 17.789 \\
Televisión por suscripción $^{1}$ & 7.611 & 6.447 & 6.888 & 7.676 & 7.511 & 9.377 \\
Acueductos $^{1}$ & 8.610 & 6.809 & 7.452 & 7.537 & 8.483 & 10.797 \\
Telefonía fija $^{1}$ & 11.440 & 9.673 & 9.183 & 9.768 & 10.932 & 12.960 \\
Internet fijo $^{1}$ & 6.165 & 6.349 & 6.325 & 6.207 & 5.689 & 6.205 \\
Gas para cocina $^{1}$ & 2.070 & 1.675 & 1.908 & 1.931 & 1.763 & 2.492 \\
Otros servicios $^{1}$ & & & & & & \\
\hline
\end{tabular}

*/ La estimación se realiza a partir de los hogares que efectivamente realizan gasto en cada servicio público.

1/ Existen diferencias significativas entre niveles de ingreso con un nivel de confianza del 95\% (ver detalle en anexo 7).

Fuente: Elaboración propia con datos de la ENIGH 2013 realizada por el INEC. 


\section{GRÁFICO 1 \\ COSTA RICA: PROPORCIÓN DEL INGRESO DE LOS HOGARES QUE SE DESTINAN A ADQUIRIR SERVICIOS PÚBLICOS REGULADOS, SEGÚN NIVEL DE INGRESO (QUINTIL). AÑO 2013}

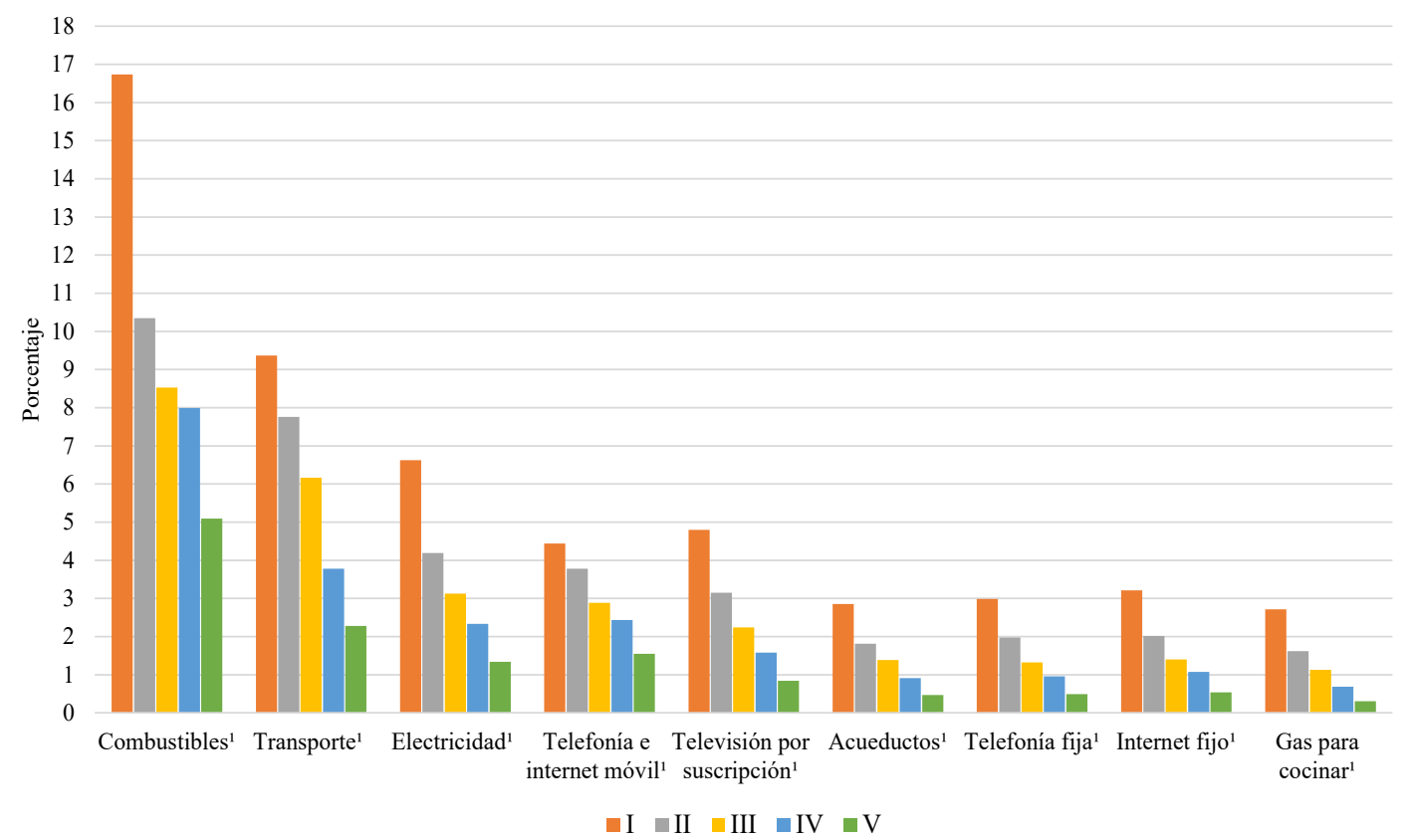

1/ Existen diferencias significativas entre niveles de ingreso con un nivel de confianza del 95\% (ver detalle en anexo 7). Fuente: Elaboración propia con datos de la ENIGH 2013 del INEC.

Análisis de grupos de hogares usuarios de bienes y servicios públicos regulados ${ }^{18}$

A partir del análisis de conglomerados ${ }^{19}$, utilizando las 10 variables de gasto en servicios públicos definidas en el presente trabajo, se obtienen cinco grupos de hogares claramente diferenciados por el gasto mensual que realizan sus miembros. En el cuadro 5, se muestra la composición del gasto total mensual en servicios públicos regulados de los grupos de hogares, la media del gasto mensual en estos servicios y su relación con el ingreso medio de los hogares. A continuación, se detallan los grupos de hogares obtenidos por estas variables.

18 Primero se evaluó el conjunto de datos y se obtuvo un valor del estadístico de Hopkins de 0,008 , por lo cual existe evidencia de que estos datos no se distribuyen aleatoriamente y pueden presentar agrupaciones relevantes. Para la selección del número de agrupaciones, se utilizó la técnica del codo (ver Anexo 12), con el que se selecciona cinco grupos, dado que entre 5 y 6 grupos no se aprecia una ganancia importante en la reducción de la suma total de la variación dentro de las agrupaciones. Respecto a estos grupos seleccionados, se obtuvo un coeficiente de silueta de 0,34 , que es considerado adecuado para el análisis. Para el estadístico de Hopkins, se utilizó se utilizó la función hopkins del paquete clustertend de YiLan y RuTong (2015), para la técnica del codo se utilizó la función fviz_nbclust del paquete factoextra de Kassambara y Mundt (2017) y para el coeficiente de silueta se utilizó la función silhouette del paquete cluster de Maechler., Rousseeuw., Struyf., Hubert y Hornik (2017).

19 Para el análisis de conglomerados se utilizó la función kmeans del paquete stats de R Core Team (2017). 


\section{CUADRO 5 \\ COSTA RICA: CARACTERIZACIÓN DEL GASTO MENSUAL EN SERVICIOS PÚBLICOS REGULADOS DE LOS HOGARES, SEGÚN GRUPOS DE HOGARES DEL ANÁLISIS DE CONGLOMERADOS. AÑO 2013}

\begin{tabular}{|c|c|c|c|c|c|}
\hline \multirow{2}{*}{ Detalle } & \multicolumn{5}{|c|}{ Grupo de hogares } \\
\hline & A & B & $\mathrm{C}$ & D & $\mathrm{E}$ \\
\hline & \multicolumn{5}{|c|}{ Distribución del gasto total mensual en servicios públicos (porcentaje) } \\
\hline Total & 100 & 100 & 100 & 100 & 100 \\
\hline Combustibles & 4,2 & 2,4 & 6,1 & 43,2 & 55,0 \\
\hline Transporte ${ }^{1}$ & 9,3 & 38,4 & 55,0 & 6,6 & 6,6 \\
\hline Electricidad ${ }^{1}$ & 30,3 & 17,9 & 11,5 & 14,2 & 10,4 \\
\hline \multicolumn{5}{|l|}{ Telefonía e Internet } & 11,5 \\
\hline \multicolumn{6}{|l|}{ Televisión por } \\
\hline suscripción ${ }^{1}$ & 11,8 & 7,8 & 5,7 & 7,3 & 5,4 \\
\hline Acueductos $^{1}$ & 12,4 & 6,7 & 4,5 & 5,1 & 3,7 \\
\hline Telefonía fija ${ }^{1}$ & 6,3 & 4,2 & 2,5 & 4,0 & 3,3 \\
\hline Internet fijo ${ }^{1}$ & 2,6 & 2,6 & 2,0 & 3,1 & 2,5 \\
\hline Gas para cocinar ${ }^{1}$ & 5,2 & 2,5 & 1,5 & 1,8 & 0,7 \\
\hline \multirow[t]{2}{*}{ Otros servicios } & 1,0 & 0,5 & 0,3 & 1,0 & 0,7 \\
\hline & \multicolumn{5}{|c|}{ Media mensual (colones corrientes) } \\
\hline Ingreso del hogar*1 & 494.533 & 699.332 & 954.722 & 1.077 .204 & 1.866 .001 \\
\hline \multirow[t]{2}{*}{$\begin{array}{l}\text { Gasto servicios públicos } \\
\text { del hogar }{ }^{1}\end{array}$} & 51.395 & 102.803 & 179.707 & 147.994 & 278.762 \\
\hline & \multicolumn{5}{|c|}{ Ingreso mensual del hogar que se destina a servicios públicos (porcentaje) } \\
\hline $\begin{array}{l}\text { Gasto servicios públicos / } \\
\text { Ingreso }^{1}\end{array}$ & 10,4 & 14,7 & 18,8 & 13,7 & 14,9 \\
\hline
\end{tabular}

1/ Existen diferencias significativas entre grupos de hogares con un nivel de confianza del $95 \%$ (ver detalle en anexo 8). */ Corresponde al ingreso corriente neto del hogar sin valor locativo.

Fuente: Elaboración propia con datos de la ENIGH 2013 del INEC.

Grupo A: hogares con gasto bajo. Estos representan el 51\% de los hogares del país y se caracterizan por destinar una proporción baja de sus gastos en servicios públicos (menor al 10,2\%) a transporte púbico y combustibles. La mayor parte del gasto total mensual en servicios públicos lo destinan a la electricidad, la cual abarca el 30\% de este gasto y, en menor medida, a la telefonía e Internet móvil, acueductos y alcantarillados y televisión por suscripción, con participaciones mayores al 10\% del gasto en servicios públicos. Este grupo presenta una media de gasto mensual en servicios públicos de 51 mil colones (la menor de los 5 grupos) y en promedio los ingresos mensuales por hogar son poco menos de 500 mil colones, por lo que estos hogares ocupan mensualmente cerca del 10,4\% de sus ingresos a adquirir servicios públicos.

Grupo B: hogares de pasajeros con gasto medio. Este grupo abarca el 20\% de los hogares del país y a diferencia del grupo anterior, destina una parte sustancial del gasto total mensual en servicios públicos al de transporte público (poco menos del 40\%); además, asigna cerca del 3\% del gasto al combustible, por lo cual es notorio que los miembros de los hogares de este grupo satisfacen sus necesidades de traslado dentro del país por medio de servicio de transporte público, principalmente. En este grupo, los servicios de electricidad y de telefonía e Internet móvil también representan una proporción importante (mayor al 15\%) del gasto total mensual en servicios públicos, alrededor del 18\% en cada caso. Estos hogares tienen una media de ingresos mensual de 700 mil colones y en promedio destinan poco más de 100 mil colones mensuales al consumo de estos servicios, lo que representa $14,7 \%$ de sus ingresos. 
Grupo C: hogares de pasajeros con gasto alto. Está constituido por el 5,4\% de los hogares del país y, como el grupo anterior, destina una proporción sustancial de su gasto mensual en servicios públicos al de transporte público, de hecho, abarca más del 50\% de gasto mensual en estos servicios; mientras que únicamente $6 \%$ de ese gasto es para el combustible. También destina una parte relevante (mayor al 9,5\%) del gasto total mensual en servicios públicos a la electricidad y telefonía e Internet móvil, pero en menor medida que el otro grupo de pasajeros. La media de ingresos de estos hogares es de 950 mil colones al mes y en promedio ocupan cerca de 180 mil colones al consumo de servicios públicos regulados, por lo cual reserva el $18,8 \%$ de sus ingresos mensuales a su consumo, lo que lo convierte en el grupo de hogares que destinan una mayor parte de sus ingresos mensuales a la adquisición de estos servicios.

Grupo D: hogares de conductores con gasto medio. Compuesto por el 15\% de los hogares del país. A diferencia de los dos grupos anteriores, consume principalmente combustible para satisfacer sus necesidades de traslado, asumiendo que este se utiliza en vehículos. En este grupo, el 43\% del gasto total mensual en servicios públicos se utiliza para adquirir combustibles; similar a los otros grupos, destina una proporción relevante del gasto en servicios públicos a la electricidad y telefonía e Internet móvil (alrededor del 14\% en cada caso). Estos hogares presentan una media de ingreso mensual de cerca de 1,1 millones de colones, en promedio destinan alrededor de 150 mil colones a la adquisición de servicios públicos, por lo cual invierten en ellos el 13,7\% de los ingresos.

Grupo E: hogares de conductores con gasto alto. Estos abarcan el 7\% de los hogares del país y asignan una proporción mayor del gasto mensual a adquirir combustibles que el grupo anterior. Este grupo destina el 55\% de su gasto mensual en servicios públicos al combustible y similar al grupo anterior, pero en menor magnitud, los servicios de electricidad y de telefonía e Internet móvil abarcan una proporción relevante del gasto en servicios públicos (alrededor del 10\%). Este grupo presenta una media de ingresos mensuales de poco más de 1,8 millones de colones y una media de gastos mensual en servicios públicos de 278 mil colones (la mayor de los 5 grupos) y ocupa cerca del 15\% de estos ingresos mensuales a adquirir estos servicios.

El grupo de "hogares con gasto bajo" (A), al ser el grupo de mayor tamaño (50\% de los hogares), se dividió en tres subgrupos de acuerdo con el nivel de ingreso de los hogares (bajo, medio y alto ${ }^{20}$ ). Como se detalla en el cuadro 6 , la composición del gasto en servicios públicos de este grupo se mantiene en los tres subgrupos (una baja proporción del gasto en servicios públicos es destinada al transporte $y$ combustibles, $y$ un alto porcentaje al servicio de electricidad, con una media de gasto en estos servicios baja), lo que refleja que estos hogares no varían de forma sustancial su patrón de gasto en servicios públicos entre los distintos niveles de ingresos. Como se indicará más adelante, esta particularidad permite identificar cuando las características socioeconómicas que diferencian al grupo de "hogares con gasto bajo" con los otros grupos se mantienen o acentúa entre sus subgrupos.

20 De acuerdo con los quintiles de ingreso, el nivel bajo (A1) comprende el primer y segundo quintil, el nivel medio (A2) el tercer quintil y el nivel alto (A3) el cuarto y quinto quintil. 


\section{CUADRO 6 \\ COSTA RICA: CARACTERIZACIÓN DEL GASTO MENSUAL EN SERVICIOS PÚBLICOS REGULADOS DE LOS HOGARES, SEGÚN SUB GRUPOS DE HOGARES CON GASTO BAJO (A). AÑO 2013}

\begin{tabular}{|c|c|c|c|c|}
\hline \multirow{2}{*}{ Detalle } & \multicolumn{4}{|c|}{ Sub grupos de hogares A } \\
\hline & A & A1 & $\mathrm{A} 2$ & A3 \\
\hline \multicolumn{5}{|c|}{ Distribución del gasto total mensual en servicios públicos (porcentaje) } \\
\hline Total & 100 & 100 & 100 & 100 \\
\hline Combustibles & 4,2 & 4,4 & 5,2 & 3,3 \\
\hline Transporte ${ }^{1}$ & 9,3 & 11,8 & 10,3 & 5,6 \\
\hline Electricidad ${ }^{1}$ & 30,3 & 33,2 & 27,5 & 28,2 \\
\hline Telefonía e Internet móvil ${ }^{1}$ & 17,0 & 14,8 & 16,7 & 19,9 \\
\hline Televisión por suscripción ${ }^{1}$ & 11,8 & 8,7 & 12,2 & 15,4 \\
\hline Acueductos $^{1}$ & 12,4 & 13,4 & 12,8 & 10,8 \\
\hline Telefonía fija ${ }^{1}$ & 6,3 & 5,1 & 6,2 & 7,9 \\
\hline Internet fijo ${ }^{1}$ & 2,6 & 1,0 & 2,5 & 4,6 \\
\hline Gas para cocinar ${ }^{1}$ & 5,2 & 6,9 & 5,5 & 2,8 \\
\hline \multirow[t]{2}{*}{ Otros servicios } & 1,0 & 0,7 & 1,1 & 1,4 \\
\hline & \multicolumn{4}{|c|}{ Media mensual (colones corrientes) } \\
\hline Ingreso del hogar*1 & 494.533 & 261.760 & 451.461 & 984.489 \\
\hline \multirow[t]{2}{*}{$\begin{array}{l}\text { Gasto medio en servicios } \\
\text { públicos }{ }^{1}\end{array}$} & 51.395 & 42.915 & 53.643 & 66.407 \\
\hline & Ingreso $\mathrm{m}$ & $r$ que se & cios públic & aje) \\
\hline $\begin{array}{l}\text { Gasto servicios públicos / } \\
\text { Ingreso }^{1}\end{array}$ & 10,4 & 16,4 & 11,9 & 6,7 \\
\hline
\end{tabular}

1/ Existen diferencias significativas entre subgrupos de "Hogares con gasto bajo" con un nivel de confianza del 95\% (ver detalle en Anexo 11). */ Corresponde al ingreso corriente neto del hogar sin valor locativo.

Fuente: Elaboración propia con datos de la ENIGH 2013 del INEC.

\section{Características socioeconómicas de los grupos de hogares establecidos ${ }^{21}$}

A continuación, se presentan algunas características socioeconómicas de los hogares, que permiten describir los grupos de hogares establecidos. Se inicia por las características relacionadas con la ubicación y los jefes de hogar, se sigue con rasgos de los miembros del hogar, condición de actividad $y$ sus ingresos.

Todos los grupos de hogares presentan una concentración mayoritaria en la zona urbana y en la región Central, con excepción del grupo de "hogares con gasto bajo", donde el 31,7\% de los hogares se encuentran en la zona rural y cerca de la mitad se ubica fuera de la región Central (cuadro 7).

En referencia al jefe del hogar, los dos grupos "conductores" presentan una mayor proporción de jefaturas masculinas (alrededor 73\% de los hogares en ambos grupos), en relación con los "hogares con gasto bajo" y "hogares de pasajeros con gasto medio", en los cuales esta cifra cae a cerca del $60 \%$ (característica que se mantiene en los subgrupos de "hogares con gasto bajo"). En términos de educación de los jefes de hogar, las diferencias más importantes se presentan para algún grado de primaria y algún grado de universitaria, categorías en las cuales se concentran los "hogares con gasto bajo" (63\%) y el de "conductores con gasto alto" (51\%) respectivamente.

21 Los datos que se exponen y se comparan entre grupos de hogares muestran diferencias significativas entre ellos con un nivel de confianza del 95\%. En los anexos 8, 9, 10 y 11 se detalla el intervalo de confianza para todas las estimaciones realizadas con un nivel de confianza del 95\%. 
Por edad de los jefes de hogar, se aprecia que el grupo de "hogares con gasto bajo" es el que presenta de forma relevante mayor edad con respecto a los otros grupos, con una media de 50 años. Los otros grupos registran promedios similares de edades de sus jefaturas, alrededor de 46 años. Adicionalmente, los "hogares con gasto bajo" presentan la mayor proporción, cerca al 30\%, de hogares con jefes con edades de 60 o más años, para los otros grupos esta cifra cae alrededor del 15\% (estas características se acentúan en los subgrupos de "hogares con gasto bajo", llegando a 52 años y al $35,4 \%$ respectivamente).

\section{CUADRO 7 \\ CARACTERÍSTICAS DE LOS HOGARES Y JEFES DE HOGAR POR GRUPOS DE HOGARES DE SERVICIOS PÚBLICOS REGULADOS. AÑO 2013.}

\begin{tabular}{|c|c|c|c|c|c|c|c|c|c|}
\hline \multirow{2}{*}{ Indicador } & \multirow{2}{*}{ Nacional } & \multicolumn{5}{|c|}{ Grupos de hogares } & \multicolumn{3}{|c|}{ Sub grupos A } \\
\hline & & A & B & $\mathrm{C}$ & $\mathrm{D}$ & $\mathrm{E}$ & A1 & $\mathrm{A} 2$ & A3 \\
\hline & \multicolumn{9}{|c|}{ Porcentaje } \\
\hline Zona & 100 & 100 & 100 & 100 & 100 & 100 & 100 & 100 & 100 \\
\hline Urbana $^{1}$ & 73,2 & 68,3 & 79,5 & 77,2 & 75,1 & 80,6 & 58,5 & 74,9 & 82,6 \\
\hline Rural $^{1}$ & 26,8 & 31,7 & 20,5 & 22,8 & 24,9 & 19,4 & 41,5 & 25,1 & 17,4 \\
\hline Región & 100 & 100 & 100 & 100 & 100 & 100 & 100 & 100 & 100 \\
\hline Central $^{1}$ & 63,0 & 55,8 & 68,0 & 69,9 & 68,4 & 80,5 & 47,7 & 60,5 & 68,4 \\
\hline Otras regiones ${ }^{1}$ & 37,0 & 44,2 & 32,0 & 30,1 & 31,6 & 19,5 & 52,3 & 39,5 & 31,6 \\
\hline Sexo jefe de hogar & 100 & 100 & 100 & 100 & 100 & 100 & 100 & 100 & 100 \\
\hline Hombre $^{1}$ & 64,1 & 61,4 & 60,6 & 62,4 & 74,0 & 72,9 & 62,4 & 59,1 & 61,1 \\
\hline Mujer ${ }^{1}$ & 35,9 & 38,6 & 39,4 & 37,6 & 26,0 & 27,1 & 37,6 & 40,9 & 38,9 \\
\hline Educación jefe hogar & 100 & 100 & 100 & 100 & 100 & 100 & 100 & 100 & 100 \\
\hline Primaria o menos ${ }^{1}$ & 50,5 & 63,3 & 48,1 & 40,2 & 32,4 & 18,5 & 76,6 & 62,0 & 38,2 \\
\hline Secundaria ${ }^{1}$ & 30,4 & 27,1 & 35,0 & 36,7 & 35,0 & 30,5 & 21,9 & 32,2 & 33,6 \\
\hline Universitaria $^{1}$ & 19,2 & 9,5 & 16,9 & 23,1 & 32,7 & 51,0 & 1,4 & 5,8 & 28,3 \\
\hline Edad del jefe de hogar & 100 & 100 & 100 & 100 & 100 & 100 & 100 & 100 & 100 \\
\hline Menos de 30 años & 11,7 & 11,8 & 12,3 & 15,2 & 11,5 & 8,1 & 12,7 & 11,0 & 10,4 \\
\hline Entre 30 y 39 años & 21,2 & 20,5 & 23,0 & 16,7 & 23,4 & 22,4 & 23,7 & 16,3 & 17,5 \\
\hline Entre 40 y 49 años $^{1}$ & 25,2 & 21,8 & 28,2 & 31,6 & 28,2 & 28,3 & 23,3 & 23,3 & 17,6 \\
\hline Entre 50 y 59 años ${ }^{1}$ & 19,2 & 16,2 & 22,0 & 24,7 & 20,4 & 23,2 & 15,1 & 15,6 & 19,0 \\
\hline Más de 60 años ${ }^{1}$ & 22,7 & 29,7 & 14,5 & 11,8 & 16,5 & 17,9 & 25,2 & 33,8 & 35,4 \\
\hline & & & & & edia & & & & \\
\hline Edad del jefe hogar ${ }^{1}$ & 47,8 & 49,7 & 45,2 & 45,1 & 46,0 & 47,1 & 47,7 & 51,7 & 52,1 \\
\hline
\end{tabular}

1/ Existen diferencias significativas entre grupos de hogares con un 95\% de confianza (ver detalle en anexo 9). Fuente: Elaboración propia con datos de la ENIGH 2013 realizada por el INEC.

Como se muestra en el cuadro 8, el grupo de "hogares con gasto bajo" presenta una media de 3 personas por hogar, siendo los hogares más pequeños en promedio, mientras que los "hogares pasajeros con gasto alto" representan a los hogares de mayor tamaño promedio, con un aproximado de 4 personas por hogar. En todos los grupos como mínimo 2 personas por hogar son perceptores de ingresos.

La composición etaria de los miembros del hogar varía de forma relevante entre el grupo de "hogares con gasto bajo" y los otros grupos. En el rango de edad de 15 a 64 años, los primeros 
concentran el 64,4\% de los miembros del hogar y los otros grupos alrededor del 74\%. Para el rango de edad 65 o más años, los "hogares con gasto bajo" abarcan el 17\% de los miembros del hogar, en los otros grupos esta cifra varía entre 4,6 y 6,8\% (característica que se acentúa en los subgrupos de "hogares con gasto bajo", llegando al 21,9\%).

La actividad económica de los miembros del hogar con edades de 15 o más años, en todos los grupos, con excepción de los "hogares con gasto bajo", revela que la población fuera de la fuerza de trabajo ronda el $29 \%$ de sus miembros, mientras que en el grupo "hogares con gasto bajo" aumenta a $41 \%$. La población ocupada de los hogares, en el grupo de "hogares con gasto bajo", abarca el 53,1\% de sus miembros, cifra sustancialmente menor a la que registran los otros grupos, donde varía entre 63,1 y $69,9 \%$.

Tomando en cuenta otras fuentes de ingresos, en el grupo de "hogares con gasto bajo" el 25\% de los hogares recibe transferencias monetarias por pensión ${ }^{22}$, cifra sustancialmente mayor al 16,3 y 17,4\% de los "hogares pasajeros con gasto medio" y "hogares conductores con gasto medio" respectivamente (característica que se acentúa en los subgrupos de "hogares con gasto bajo", llegando al 32,2\%). Además, en relación con ayudas por medio de transferencias monetarias ${ }^{23}$ recibidas por los hogares, los grupos de "hogares con gasto bajo" y "hogares pasajeros con gasto medio" poseen un 6\% de sus hogares que reciben estas ayudas, mientras que en los "hogares conductores" esta cifra varía entre 0,4 y $1,9 \%$.

Los dos grupos de "hogares conductores" mayoritariamente pertenecen al quinto quintil de ingresos (hogares con mayores ingresos), con el 64 y 32,9\% en cada caso; mientras los "hogares con gasto bajo", se concentran en el primer quintil de ingreso (hogares con menores ingresos) con el 30\% de hogares en este grupo. Por su parte, el grupo de "hogares pasajeros con gasto medio" posee una parte importante (mayor al 20\%) de sus hogares en el segundo, tercer y cuarto quintil de ingresos y el grupo de "hogares pasajeros con gasto alto" se agrupan principalmente en el tercer quintil, con el $31,4 \%$ de los hogares. 
CUADRO 8

CARACTERÍSTICAS DE LOS MIEMBROS DEL HOGAR Y MEDIOS DE INGRESOS POR GRUPOS DE HOGARES DE SERVICIOS PÚBLICOS REGULADOS. AÑO 2013.

\begin{tabular}{|c|c|c|c|c|c|c|c|c|c|}
\hline \multirow{2}{*}{ Indicador $^{1}$} & \multirow{2}{*}{ Nacional } & \multicolumn{5}{|c|}{ Grupos de hogares } & \multicolumn{3}{|c|}{ Sub grupos A } \\
\hline & & A & B & $\mathrm{C}$ & D & $\mathrm{E}$ & $\mathrm{A} 1$ & $\mathrm{~A} 2$ & A3 \\
\hline & \multicolumn{9}{|c|}{ Media } \\
\hline Miembros del hogar & 3,4 & 3,1 & 3,7 & 4,1 & 3,4 & 3,5 & 3,7 & 2,8 & 2,2 \\
\hline \multirow{2}{*}{ Perceptores de ingresos } & 2,2 & 2,0 & 2,4 & 2,7 & 2,2 & 2,2 & 2,1 & 2,0 & 1,7 \\
\hline & \multicolumn{9}{|c|}{ Porcentaje } \\
\hline Grupos etarios miembros del hogar & 100 & 100 & 100 & 100 & 100 & 100 & 100 & 100 & 100 \\
\hline Menores de 15 años & 19,4 & 18,6 & 21,0 & 20,2 & 19,5 & 19,2 & 26,1 & 14,3 & 7,0 \\
\hline Entre 15 y 64 años & 69,1 & 64,4 & 73,3 & 75,2 & 73,6 & 74,7 & 60,5 & 65,6 & 71,1 \\
\hline Entre 65 o más años & 11,6 & 17,0 & 5,6 & 4,6 & 6,8 & 6,0 & 13,4 & 20,1 & 21,9 \\
\hline $\begin{array}{l}\text { Condición de actividad miembros del } \\
\text { hogar }\end{array}$ & 100 & 100 & 100 & 100 & 100 & 100 & 100 & 100 & 100 \\
\hline Ocupados & 59,5 & 53,1 & 63,1 & 67,4 & 67,4 & 69,9 & 46,1 & 54,1 & 66,2 \\
\hline Desempleados & 4,7 & 5,2 & 5,4 & 4,5 & 3,9 & 1,9 & 6,8 & 4,8 & 2,4 \\
\hline Fuera de la fuerza de trabajo & 35,8 & 41,6 & 31,5 & 28,1 & 28,7 & 28,3 & 47,1 & 41,1 & 31,3 \\
\hline Hogares que reciben pensión & 100 & 100 & 100 & 100 & 100 & 100 & 100 & 100 & 100 \\
\hline Si reciben & 20,9 & 24,7 & 16,3 & 17,3 & 17,4 & 17,9 & 19,9 & 32,2 & 28,7 \\
\hline No reciben & 79,1 & 75,3 & 83,7 & 82,7 & 82,6 & 82,1 & 80,1 & 67,8 & 71,3 \\
\hline Hogares reciben ayuda Inst. públicas & 100 & 100 & 100 & 100 & 100 & 100 & 100 & 100 & 100 \\
\hline Si reciben & 5,0 & 6,6 & 5,6 & 4,4 & 1,9 & 0,4 & 10,6 & 3,5 & 1,0 \\
\hline No reciben & 95,0 & 93,4 & 94,4 & 95,6 & 98,1 & 99,6 & 89,4 & 96,5 & 99,0 \\
\hline Quintil de ingresos de los hogares & 100 & 100 & 100 & 100 & 100 & 100 & 100 & 100 & 100 \\
\hline Primero & 20,0 & 30,0 & 15,0 & 8,5 & 7,4 & 1,9 & 56,7 & 0,0 & 0,0 \\
\hline Segundo & 20,0 & 23,0 & 25,3 & 18,1 & 13,3 & 3,3 & 43,3 & 0,0 & 0,0 \\
\hline Tercero & 20,0 & 20,0 & 23,7 & 31,4 & 17,3 & 9,7 & 0,0 & 100,0 & 0,0 \\
\hline Cuarto & 20,0 & 15,5 & 23,5 & 21,3 & 29,1 & 21,2 & 0,0 & 0,0 & 57,6 \\
\hline Quinto & 20,0 & 11,4 & 12,5 & 20,7 & 32,9 & 64,0 & 0,0 & 0,0 & 42,4 \\
\hline
\end{tabular}

1/ Todas las categorías presentan diferencias significativas entre grupos de hogares con un 95\% de confianza (ver detalle en anexo 10).

Fuente: Elaboración propia con datos de la ENIGH 2013 realizada por el INEC.

22 Se crea una variable dicotómica para separar a los hogares que recibieron transferencias monetarias por pensión de Invalides, Vejes y Muerte (IVM) o del régimen no contributivo y los que no reciben.

23 Se crea una variable dicotómica para separar a los hogares que reciben ingresos por transferencias por ayuda de Instituciones Públicas. 


\section{CONCLUSIONES}

En el año 2013, los hogares de Costa Rica destinaron alrededor de 1,8 billones de colones en la adquisición de servicios públicos regulados por la Aresep y la Sutel, lo que es equivalente a 7,2\% del PIB de ese año. Esta cifra por sí sola no es despreciable y menos aún si se considera que estos servicios son de interés general, esenciales para el desarrollo humano, responsabilidad última del Estado y se financian directamente por los usuarios que los adquieren por medio de tarifas y precios regulados. A nivel nacional, el gasto total en servicios públicos regulados se concentra en combustibles, transporte público, electricidad y telefonía e Internet móvil, con el 75\% del gasto en estos cuatro servicios. En promedio los hogares del país ocupan 106 mil colones de sus ingresos mensuales $(13,4 \%)$ en la compra de servicios públicos regulados.

La distribución del gasto total en servicios públicos entre los distintos servicios presenta variaciones principalmente entre regiones de planificación y por nivel de ingreso de los hogares, mientras que por zona de residencia se observan pocos cambios. La distribución de gasto total en servicios públicos varía fundamentalmente entre la región Central y las otras regiones; se presentan variaciones significativas entre distintas regiones en los servicios de combustibles (entre el 20 y $26 \%$ ), electricidad (entre 16,6 y 20\%), televisión por suscripción (entre 5,6 y 8,4\%), acueductos y alcantarillados (5,3\% y 8\%) y gas para cocinar (entre 1,7 y 5,5\%), en los servicios de transporte público y telefonía e Internet móvil no se aprecian variaciones significativas. Los cambios más pronunciados se presentan entre los hogares de menores y mayores ingresos, en el gasto en combustibles (entre 11,1 y 36,2\%), transporte público (entre 11,5 y 23\%), electricidad (entre 14,1 y 26,6\%), acueductos y alcantarillados (entre 4,9 y 10,1\%) y gas para cocinar (0,9\% y 5,3\%); en general todos los servicios varían de forma significativa, con excepción de telefonía fija. Este patrón del gasto en servicios públicos en relación con la ubicación y condición económica de los hogares coincide con el obtenido por Amarante y Ferrando (2011) para Uruguay.

El impacto de los servicios públicos regulados sobre el presupuesto de los hogares es relevante y muestra variaciones importantes tanto por zona, regiones de planificación como por nivel de ingreso de los hogares, donde este impacto se profundiza. El gasto mensual en servicios públicos regulados representa entre el 12,8 y 16,7\% de los ingresos mensuales de los hogares en la zona urbana y rural respectivamente. En la región Central los hogares destinan un $12,7 \%$ de sus ingresos mensuales en servicios públicos, mientras en la región Chorotega y Pacífico Central esta cifra alcanza el 16\%. En relación con el nivel de ingresos de los hogares, el impacto de los servicios públicos en el presupuesto de los hogares llega a representar el 24,5 y el 20\% de los ingresos mensuales de los hogares de menores recursos (primer y segundo quintil respectivamente), mientras que en aquellos con mayores ingresos esta cifra cae significativamente al 9,5\%. Dicha característica a nivel general concuerda con la literatura revisada tanto a nivel nacional, como para Uruguay y Colombia.

El gasto mensual de los hogares de Costa Rica en servicios públicos regulados permitió identificar cinco grupos de hogares, de igual forma que el PEN (2017); sin embargo, se obtuvieron resultados distintos en cuanto al número de grupos y su composición, lo cual no es poco usual, más aun si se considera que no se utilizaron las mismas variables. En el cuadro 9, se presenta un resumen sobre el patrón de gasto en servicios públicos de los grupos mencionados y las características socioeconómicas que los distinguen.

Como se mencionó, el principal gasto en servicios públicos para el grupo denominado "hogares con gasto bajo" es la electricidad (alrededor del 30\%), siguen en importancia la telefonía e Internet móvil, acueductos y alcantarillados y televisión por suscripción (con más del 10\% del gasto cada uno). Este grupo presenta una baja proporción de gasto en transporte público y combustible comparado con los otros y su media de gasto en servicios públicos es baja (poco más de 51 mil colones). Los cuatro grupos de hogares restantes se distinguen entre ellos principalmente por su gasto en transporte público ("hogares pasajeros") y combustibles ("hogares conductores") y tienen en común la electricidad y telefonía e Internet móvil como servicios que implican gastos relevantes (cercanos al 10\%). 
Una de las características relacionadas con el patrón de gasto del grupo de "hogares con gasto bajo" y que lo distinguen de los otros grupos de hogares son la presencia de las jefaturas de mayor edad (50 años) y la mayor proporción hogares con jefaturas con edades entre 60 o más años (cerca al 30\%), cifras que son menores en los otros grupos (alrededor de 46 años y 15\%). La composición etaria de los miembros del hogar es otro factor, mientras que el grupo de "hogares con gasto bajo" presenta relativamente la mayor proporción (17\%) de miembros con edades de 65 o más años, los otros grupos concentran cerca del $5 \%$ de sus miembros en este rango. Recibir ingresos por pensión también diferencia, debido a que cerca del 25\% de los "hogares con gasto bajo" recibe pensión, en los otros grupos esta cifra ronda el 17\%. Características como el número de miembros del hogar, estar o no en la fuerza de trabajo, en condición de ocupado y recibir ayuda de instituciones públicas por medio de transferencias monetarias, permiten diferenciar al grupo de "hogares con gasto bajo" de los otros; sin embargo, estas características no se mantienen ni se acentúan en los subgrupos de "hogares con gasto bajo" dando evidencia de no estar relacionadas con el patrón de gasto en servicios públicos de este grupo.

CUADRO 9

COMPARACIÓN RELATIVA ENTRE GRUPOS DE HOGARES DE SERVICIOS PÚBLICOS REGULADOS SEGÚN CARACTERÍSTICAS DE INTERÉS.

\begin{tabular}{|c|c|c|c|c|c|}
\hline \multirow[b]{2}{*}{ Característica } & \multicolumn{5}{|c|}{ Grupo } \\
\hline & Gasto bajo & $\begin{array}{l}\text { Pasajeros gasto } \\
\text { medio }\end{array}$ & $\begin{array}{l}\text { Pasajeros gasto } \\
\text { alto }\end{array}$ & $\begin{array}{l}\text { Conductores } \\
\text { gasto medio }\end{array}$ & $\begin{array}{c}\text { Conductores } \\
\text { gasto alto }\end{array}$ \\
\hline $\begin{array}{l}\text { Principal gasto en } \\
\text { servicios públicos }\end{array}$ & Electricidad & Transporte & Transporte & Combustible & Combustible \\
\hline $\begin{array}{l}\text { Otros gastos en } \\
\text { servicios públicos } \\
(>10 \%)\end{array}$ & $\begin{array}{l}\text { Telefonía e Internet } \\
\text { móvil } \\
\text { Acueductos y } \\
\text { alcantarillados } \\
\text { Televisión por } \\
\text { suscripción }\end{array}$ & $\begin{array}{l}\text { Electricidad } \\
\text { Telefonía e } \\
\text { Internet móvil }\end{array}$ & $\begin{array}{l}\text { Electricidad } \\
\text { Telefonía e } \\
\text { Internet móvil }\end{array}$ & $\begin{array}{l}\text { Electricidad } \\
\text { Telefonía e } \\
\text { Internet móvil }\end{array}$ & $\begin{array}{l}\text { Electricidad } \\
\text { Telefonía e } \\
\text { Internet móvil }\end{array}$ \\
\hline $\begin{array}{l}\text { Gasto medio en } \\
\text { servicios públicos }\end{array}$ & Bajo & Medio & Alto & Medio & Alto \\
\hline Ingreso medio & Medio-Bajo & Medio & Medio-Alto & Medio-Alto & Alto \\
\hline $\begin{array}{l}\text { Número de miembros } \\
\text { del hogar }\end{array}$ & Bajo & Medio & Alto & Medio & Medio \\
\hline $\begin{array}{l}\text { Miembros con edades } \\
\text { entre } 15 \text { y } 64 \text { años }\end{array}$ & Bajo & Alto & Alto & Alto & Alto \\
\hline $\begin{array}{l}\text { Miembros con edades } \\
\text { de } 65 \text { o más años }\end{array}$ & Alto & Bajo & Bajo & Bajo & Bajo \\
\hline Reciben pensión & Medio-Alto & Medio & Medio & Medio & Medio \\
\hline Vehículo del hogar & Bajo & Bajo & Bajo & Alto & Alto \\
\hline
\end{tabular}

Fuente: Elaboración propia a partir de los resultados del análisis de conglomerados. 


\section{REFERENCIAS}

Amarante, V. y Ferrando, M. (2011). Consumo de servicios de energía y agua en la población uruguaya. Uruguay. Universidad de la República.

Centro de Investigaciones para el Desarrollo (2004). Equidad en las tarifas de los servicios públicos. Impacto en la capacidad de pago de los hogares de Bogotá D. C. Bogota, Colombia: Universidad Nacional de Colombia.

Código Municipal. (Ley N $\left.\mathrm{N}^{\circ} 794,1998\right)$. Costa Rica

Han, J., Kamber, M. y Pei, J. (2012). Data mining: concepts and techniques. (3.a ed.). Massachusetts, Estados Unidos: Elsevier.

Instituto Nacional de Estadística y Censos (2014). Archivos de datos Encuesta Nacional de Ingresos y Gastos de los Hogares 2013. [Obtenido en Programa acelerador de datos del INEC]. Recuperado de http://www.inec.go.cr/bases-de-datos-y-documentacion [Consulta 2 mar. 2017].

Instituto Nacional de Estadística y Censos (2014). Encuesta Nacional de Ingresos y Gastos de los Hogares 2013: Principales resultados. San José, Costa Rica: Autor.

Instituto Nacional de Estadística y Censos (2014). Encuesta Nacional de Ingresos y Gastos de los Hogares 2013: Metodología. San José, Costa Rica: Autor.

Instituto Nacional de Estadística y Censos (s.f.). Encuesta Nacional de Ingresos y Gastos de los Hogares ENIGH 2013: Códigos de bienes y servicios. [pdf, obtenido en Programa acelerador de datos del INEC]. Recuperado de http://www.inec.go.cr/bases-de-datos-y-documentacion [Consulta 2 mar. 2017].

Instituto Nacional de Estadística y Censos (s.f.). Encuesta Nacional de Ingresos y Gastos de los Hogares ENIGH 2013: Códigos de bienes y servicios. [pdf, obtenido en Programa acelerador de datos del INEC]. Recuperado de http://www.inec.go.cr/bases-de-datos-y-documentacion [Consulta 2 mar. 2017].

Kassambara, A. y Mundt, F. (2017). factoextra: Extract and Visualize the Results of Multivariate 
Data Analyses. [R package version 1.0.5]. Recuperado de https:/CRAN.R-project.org/ package $=$ factoextra

Kaufman, L. y Rousseeuw, P. (1990). Finding Groups in Data: An Introduction To Cluster Analysis. Nueva Jersy, Estados Unidos: John Wiley \& Sons. https://doi.org/10.1002/9780470316801

Lasheras, M.A. (1999). La regulación económica de los servicios públicos. Barcelona, España: Ariel.

Ley de Creación del Consejo Nacional de Vialidad. (Ley Nº 7798, 1998). Costa Rica

Ley de Fortalecimiento y Modernización del Sector Telecomunicaciones de las Entidades Públicas. (Ley $\left.\mathrm{N}^{\circ} 8660,2008\right)$. Costa Rica

Ley de la Autoridad Reguladora de los Servicios Públicos. (Ley N 7593, 1996). Costa Rica

Ley de Tránsito por Vías Públicas Terrestres y Seguridad Vial. (Ley N 9078, 2012). Costa Rica

Ley General de Telecomunicaciones. (Ley N 8642, 2008). Costa Rica

Maechler, M., Rousseeuw, P., Struyf, A., Hubert, M. y Hornik, K.(2017). Cluster: Cluster Analysis Basics and Extensions. [R package version 2.0.6].

Naciones Unidas (2015). Transformar nuestro mundo: la Agenda 2030 para el Desarrollo Sostenible. Resolución 70/1. Naciones Unidas: Autor.

Procuraduría General de la República (2000). Dictamen : 152 del 07/07/2000 . [pdf]. Recuperado de http://www.pgrweb.go.cr/scij/Busqueda/Normativa/pronunciamiento/pro_ficha.aspx?Param1 $=$ PRD\&param2=3\&nParam6=1\&nDictamen=8707\&1Resultado=28\&strSimp=simple\&strTip $\mathrm{M}=\mathrm{T}$ [Consulta 10 mar. 2017].

Programa Estado de la Nación (2017). Decimotercer Informe Estado de la Nación en Desarrollo Humano Sostenible. San José, Costa Rica: Autor.

R Core Team (2017). R: A language and environment for statistical computing. $R$ Foundation for Statistical Computing, Vienna, Austria. Recuperado de https://www.R-project.org/.

Rodríguez-Arguello, P. (2001). Desarrollo y Regulación de los Servicios Públicos en Costa Rica. San José, Costa Rica: Autoridad Reguladora de los Servicios Públicos.

Rozas-Balbontín, P. y Hantke-Domas, M. (2013). Gestión pública y servicios públicos. Notas sobre el concepto tradicional de servicios públicos. (Serie Recursos Naturales e Infraestructura $\mathrm{N}^{\circ}$ 162). Santiago de Chile, Chile: Naciones Unidas. CEPAL.

Solanes, M. (1999). Servicios públicos y regulación. Consecuencias legales de las fallas del mercado. 
(Serie Recursos Naturales e Infraestructura $\mathrm{N}^{\circ}$ 2). Santiago de Chile, Chile. Naciones Unidas. CEPAL.

Superintendencia de Telecomunicaciones (2014). Estadísticas del sector de telecomunicaciones. Informe 2010-2013. Costa Rica. San José, Costa Rica: Autor.

YiLan, L. y RuTong, Z. (2015). clustertend: Check the Clustering Tendency. [R package version 1.4]. Recuperado de https://CRAN.R-project.org/package=clustertend. 


\section{ANEXOS}

ANEXO 1

DETALLE DE LAS VARIABLES DE SERVICIOS PÚBLICOS REGULADOS CREADAS, ARTÍCULOS QUE LAS COMPONE Y SU COMPOSICIÓN PORCENTUAL POR ARTÍCULO

\begin{tabular}{|c|c|c|}
\hline Variable de servicio público regulado/Detalle de artículo ENIGH 2013 & Código artículo ENIGH & Porcentaje $^{1}$ \\
\hline Electricidad & - & 100 \\
\hline Electricidad & 1631 & 100 \\
\hline Acueductos y alcantarillados & - & 100 \\
\hline Suministro de agua $y$ alcantarillado & 1651 & 100 \\
\hline Gas para cocinar & - & 100 \\
\hline Recarga de gas licuado (cocina) & 1633 & 100 \\
\hline Combustibles & - & 100 \\
\hline Gasolina regular & 1534 & 46,66 \\
\hline Gasolina súper & 1535 & 37,03 \\
\hline Diésel & 1532 & 13,80 \\
\hline Gasolina plus & 1536 & 2,51 \\
\hline Gas licuado empleado para automóviles y otros medios de transporte & 1533 & 0,01 \\
\hline Transporte & - & 100 \\
\hline Transporte regular en bus dentro de la misma provincia & 1546 & 45,89 \\
\hline Transporte regular privado en taxi & 1545 & 20,97 \\
\hline Transporte regular bus o microbús entre provincias & 1544 & 16,49 \\
\hline Transporte escolar & 1877 & 9,95 \\
\hline Transporte regular colectivo (taxis o carros privados y taxi pirata) & 1540 & 5,04 \\
\hline Transporte terrestre en taxi dentro del país & 4658 & 0,98 \\
\hline Transporte regular en lancha & 1542 & 0,28 \\
\hline Transporte regular en ferry & 1541 & 0,22 \\
\hline Transporte regular en tren & 1543 & 0,16 \\
\hline Transporte interurbano en bus o microbús (dentro del país) & 4655 & 0,02 \\
\hline Transporte al interior del país vía marítima & 4653 & 0,00 \\
\hline Televisión por cable & - & 100 \\
\hline Tarifa de televisión por cable & 1684 & 92,76 \\
\hline Tarifa de televisión por satélite & 1685 & 6,94 \\
\hline Tarifa de televisión por IP & 1686 & 0,29 \\
\hline Telefonía fija & - & 100 \\
\hline Servicio telefónico residencial del hogar & 1681 & 98,92 \\
\hline Compra de tarjeta de teléfono & 1580 & 1,07 \\
\hline Llamada en teléfonos públicos, hoteles, cafés, restaurantes y otros & 1581 & 0,01 \\
\hline Internet fijo & - & 100 \\
\hline Servicio de Internet residencial & 1680 & 99,24 \\
\hline Pago por uso del servicio de Internet en Café Internet o similares & 1582 & 0,76 \\
\hline Telefonía e Internet móvil & - & 100 \\
\hline
\end{tabular}




\begin{tabular}{|c|c|c|}
\hline Variable de servicio público regulado/Detalle de artículo ENIGH 2013 & Código artículo ENIGH & Porcentaje $^{1}$ \\
\hline Recarga celular (para telefonía, internet o servicios BlackBerry) & 1583 & 46,50 \\
\hline Servicio telefónico celular pospago sin plan & 1709 & 32,92 \\
\hline Servicio telefónico celular pospago con plan & 1708 & 18,67 \\
\hline Data card sin plan & 1701 & 1,09 \\
\hline Data card con plan & 1700 & 0,32 \\
\hline Pago mensual por uso de Internet celular & 1710 & 0,22 \\
\hline Datos para table con plan & 1702 & 0,14 \\
\hline Facilidad BlackBerry pospago & 1704 & 0,06 \\
\hline Data card prepago (servicio) & 1584 & 0,06 \\
\hline Datos para table sin plan & 1703 & 0,02 \\
\hline Roaming pospago (internet $y$ voz) & 1707 & 0,00 \\
\hline Otros servicios & - & 100 \\
\hline Revisión técnica de vehículos (incluye reinspección) & 4773 & 52,81 \\
\hline Instalación o reconexión a Internet & 1675 & 20,16 \\
\hline Peaje & 1538 & 14,61 \\
\hline Instalación o reconexión de medidor de agua & 1650 & 4,50 \\
\hline Instalación de servicio de televisión por cable & 1674 & 4,05 \\
\hline Instalación o reconexión del medidor de electricidad & 1630 & 2,64 \\
\hline Instalación o reconexión de línea telefónica residencial & 1676 & 1,23 \\
\hline
\end{tabular}

1/ Porcentaje en relación con el gasto mensual total en cada variable de servicios público definida. Fuente: Elaboración propia con información del INEC. 
ANEXO 2.

ESTIMACIÓN DEL GASTO TOTAL MENSUAL DE LOS HOGARES EN SERVICIOS PÚBLICOS REGULADOS, SU DISTRIBUCIÓN Y PORCENTAJE DE HOGARES QUE LOS ADQUIEREN SEGÚN ZONA Y A NIVEL NACIONAL. AÑO 2013

\begin{tabular}{|c|c|c|c|c|c|c|c|c|c|}
\hline \multirow{3}{*}{ Servicio $^{12}$} & \multirow{2}{*}{\multicolumn{3}{|c|}{ Nacional }} & \multicolumn{6}{|c|}{ Zona } \\
\hline & & & & \multicolumn{3}{|c|}{ Urbano } & \multicolumn{3}{|c|}{ Rural } \\
\hline & $\begin{array}{l}\text { Límite } \\
\text { inferior }\end{array}$ & Media & $\begin{array}{r}\text { Límite } \\
\text { superior }\end{array}$ & $\begin{array}{l}\text { Límite } \\
\text { inferior }\end{array}$ & Media & $\begin{array}{l}\text { Límite } \\
\text { superior }\end{array}$ & $\begin{array}{l}\text { Límite } \\
\text { inferior }\end{array}$ & Media & $\begin{array}{l}\text { Límite } \\
\text { superior }\end{array}$ \\
\hline & \multicolumn{9}{|c|}{ Gasto total mensual en servicios públicos (millones de colones) } \\
\hline $\begin{array}{l}\text { Servicios } \\
\text { públicos }\end{array}$ & 142.580 & 148.180 & 153.780 & 113.489 & 118.817 & 124.144 & 27.637 & 29.363 & 31.089 \\
\hline Combustibles & 33.441 & 36.380 & 39.318 & 25.862 & 28.619 & 31.375 & 6.743 & 7.761 & 8.779 \\
\hline Transporte & 25.637 & 27.642 & 29.646 & 19.916 & 21.805 & 23.695 & 5.167 & 5.836 & 6.506 \\
\hline Electricidad & 25.155 & 26.064 & 26.972 & 19.766 & 20.630 & 21.493 & 5.152 & 5.434 & 5.716 \\
\hline $\begin{array}{l}\text { Telefonía } \\
\text { e Internet } \\
\text { móvil }\end{array}$ & 20.458 & 21.700 & 22.941 & 16.394 & 17.588 & 18.781 & 3.770 & 4.112 & 4.454 \\
\hline $\begin{array}{l}\text { Televisión por } \\
\text { suscripción }\end{array}$ & 10.983 & 11.548 & 12.113 & 9.559 & 10.085 & 10.612 & 1.258 & 1.463 & 1.668 \\
\hline Acueductos & 9.453 & 9.950 & 10.447 & 7.685 & 8.137 & 8.589 & 1.607 & 1.814 & 2.020 \\
\hline Telefonía fija & 5.886 & 6.249 & 6.611 & 4.748 & 5.087 & 5.427 & 1.033 & 1.161 & 1.289 \\
\hline Internet fijo & 3.559 & 3.851 & 4.143 & 3.291 & 3.575 & 3.860 & 210 & $276^{*}$ & 341 \\
\hline $\begin{array}{l}\text { Gas para } \\
\text { cocinar }\end{array}$ & 3.431 & 3.680 & 3.929 & 2.159 & 2.383 & 2.607 & 1.188 & 1.297 & 1.406 \\
\hline \multirow[t]{2}{*}{$\begin{array}{l}\text { Otros } \\
\text { servicios }\end{array}$} & 966 & 1.117 & 1.268 & 762 & 907 & 1.053 & 170 & 210 & 249 \\
\hline & \multicolumn{9}{|c|}{ Distribución del gasto total mensual en servicios públicos (porcentaje) } \\
\hline $\begin{array}{l}\text { Servicios } \\
\text { públicos }\end{array}$ & 100 & 100 & 100 & 100 & 100 & 100 & 100 & 100 & 100 \\
\hline Combustibles & 23,1 & 24,6 & 26,0 & 22,3 & 24,1 & 25,8 & 24,0 & 26,4 & 28,9 \\
\hline Transporte & 17,5 & 18,7 & 19,8 & 17,0 & 18,4 & 19,7 & 17,8 & 19,9 & 21,9 \\
\hline Electricidad & 17,1 & 17,6 & 18,1 & 16,8 & 17,4 & 18,0 & 17,5 & 18,5 & 19,5 \\
\hline $\begin{array}{l}\text { Telefonía } \\
\text { e Internet } \\
\text { móvil }\end{array}$ & 14,0 & 14,6 & 15,2 & 14,1 & 14,8 & 15,5 & 12,9 & 14,0 & 15,1 \\
\hline $\begin{array}{l}\text { Televisión por } \\
\text { suscripción }\end{array}$ & 7,5 & 7,8 & 8,1 & 8,1 & 8,5 & 8,8 & 4,4 & 5,0 & 5,5 \\
\hline Acueductos & 6,4 & 6,7 & 7,0 & 6,5 & 6,8 & 7,2 & 5,5 & 6,2 & 6,8 \\
\hline Telefonía fija & 4,0 & 4,2 & 4,4 & 4,0 & 4,3 & 4,5 & 3,6 & 4,0 & 4,4 \\
\hline Internet fijo & 2,4 & 2,6 & 2,8 & 2,8 & 3,0 & 3,2 & 0,7 & $0,9^{*}$ & 1,1 \\
\hline $\begin{array}{l}\text { Gas para } \\
\text { cocinar }\end{array}$ & 2,3 & 2,5 & 2,7 & 1,8 & 2,0 & 2,2 & 4,0 & 4,4 & 4,8 \\
\hline $\begin{array}{l}\text { Otros } \\
\text { servicios }\end{array}$ & 0,7 & 0,8 & 0,9 & 0,6 & 0,8 & 0,9 & 0,6 & 0,7 & 0,8 \\
\hline
\end{tabular}




\begin{tabular}{|c|c|c|c|c|c|c|c|c|c|}
\hline \multirow{3}{*}{ Servicio $^{12}$} & \multirow{2}{*}{\multicolumn{3}{|c|}{ Nacional }} & \multicolumn{6}{|c|}{ Zona } \\
\hline & & & & \multicolumn{3}{|c|}{ Urbano } & \multicolumn{3}{|c|}{ Rural } \\
\hline & $\begin{array}{l}\text { Límite } \\
\text { inferior }\end{array}$ & Media & $\begin{array}{r}\text { Límite } \\
\text { superior }\end{array}$ & $\begin{array}{l}\text { Límite } \\
\text { inferior }\end{array}$ & Media & $\begin{array}{r}\text { Límite } \\
\text { superior }\end{array}$ & $\begin{array}{l}\text { Límite } \\
\text { inferior }\end{array}$ & Media & $\begin{array}{l}\text { Límite } \\
\text { superior }\end{array}$ \\
\hline & \multicolumn{9}{|c|}{ Hogares que adquieren servicios públicos (porcentaje) } \\
\hline $\begin{array}{l}\text { Servicios } \\
\text { públicos }\end{array}$ & 100 & 100 & 100 & 100 & 100 & 100 & 99 & 100 & 100 \\
\hline Combustibles & 30,2 & 32,2 & 34,1 & 29,5 & 31,9 & 34,3 & 29,9 & 33,0 & 36,1 \\
\hline Transporte & 56,5 & 58,5 & 60,5 & 57,9 & 60,2 & 62,6 & 50,0 & 53,6 & 57,3 \\
\hline Electricidad & 98,9 & 99,2 & 99,4 & 99,4 & 99,6 & 99,8 & 97,2 & 98,0 & 98,9 \\
\hline $\begin{array}{l}\text { Telefonía } \\
\text { e Internet } \\
\text { móvil }\end{array}$ & 75,8 & 77,5 & 79,2 & 77,6 & 79,6 & 81,6 & 68,7 & 71,8 & 74,9 \\
\hline $\begin{array}{l}\text { Televisión por } \\
\text { suscripción }\end{array}$ & 53,4 & 55,9 & 58,3 & 62,5 & 65,5 & 68,5 & 24,9 & 29,5 & 34,1 \\
\hline Acueductos & 92,2 & 93,6 & 95,0 & 96,0 & 97,1 & 98,1 & 79,8 & 84,2 & 88,5 \\
\hline Telefonía fija & 49,6 & 52,0 & 54,3 & 53,8 & 56,7 & 59,6 & 34,9 & 39,0 & 43,0 \\
\hline Internet fijo & 22,3 & 24,1 & 25,9 & 27,7 & 30,2 & 32,8 & 5,6 & $7,3^{*}$ & 9,0 \\
\hline $\begin{array}{l}\text { Gas para } \\
\text { cocinar }\end{array}$ & 40,7 & 42,7 & 44,7 & 36,0 & 38,5 & 41,0 & 50,9 & 54,3 & 57,7 \\
\hline $\begin{array}{l}\text { Otros } \\
\text { servicios }\end{array}$ & 36,5 & 38,6 & 40,8 & 37,9 & 40,6 & 43,3 & 30,0 & 33,3 & 36,7 \\
\hline
\end{tabular}

$1 /(*)$ coeficiente de variación igual o mayor al 10\% y menor al 20\%, (**) coeficiente de variación igual o mayor al $20 \%$. 2/ Intervalo de confianza se estima con un nivel de confianza del 95\%. En cada variable o indicador estimado cuando los límites de confianza de las categorías analizadas se traslapan existe evidencia de que esas categorías no difieren de forma significativa.

Fuente: Elaboración propia con datos de la ENIGH 2013 del INEC. 


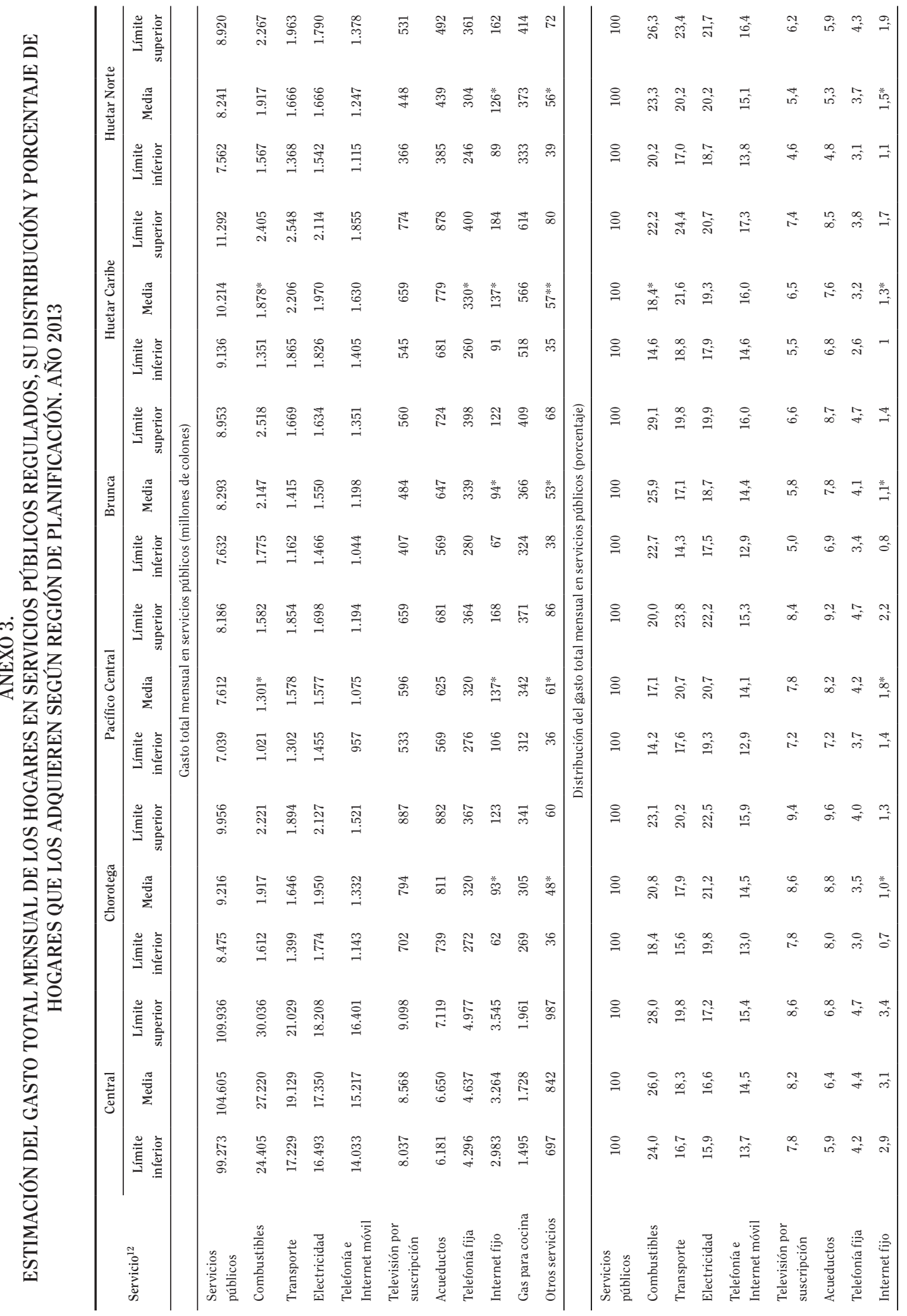




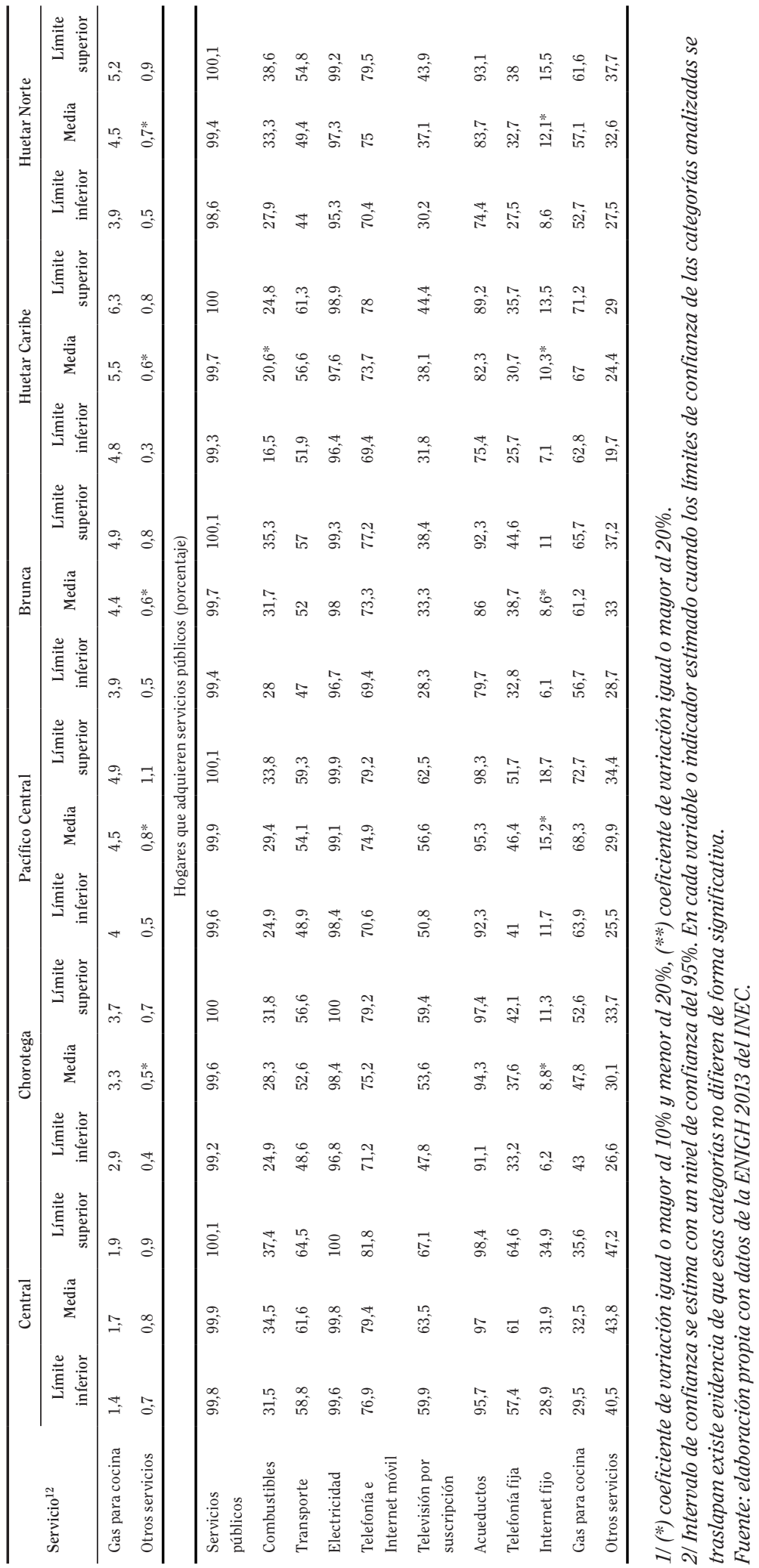




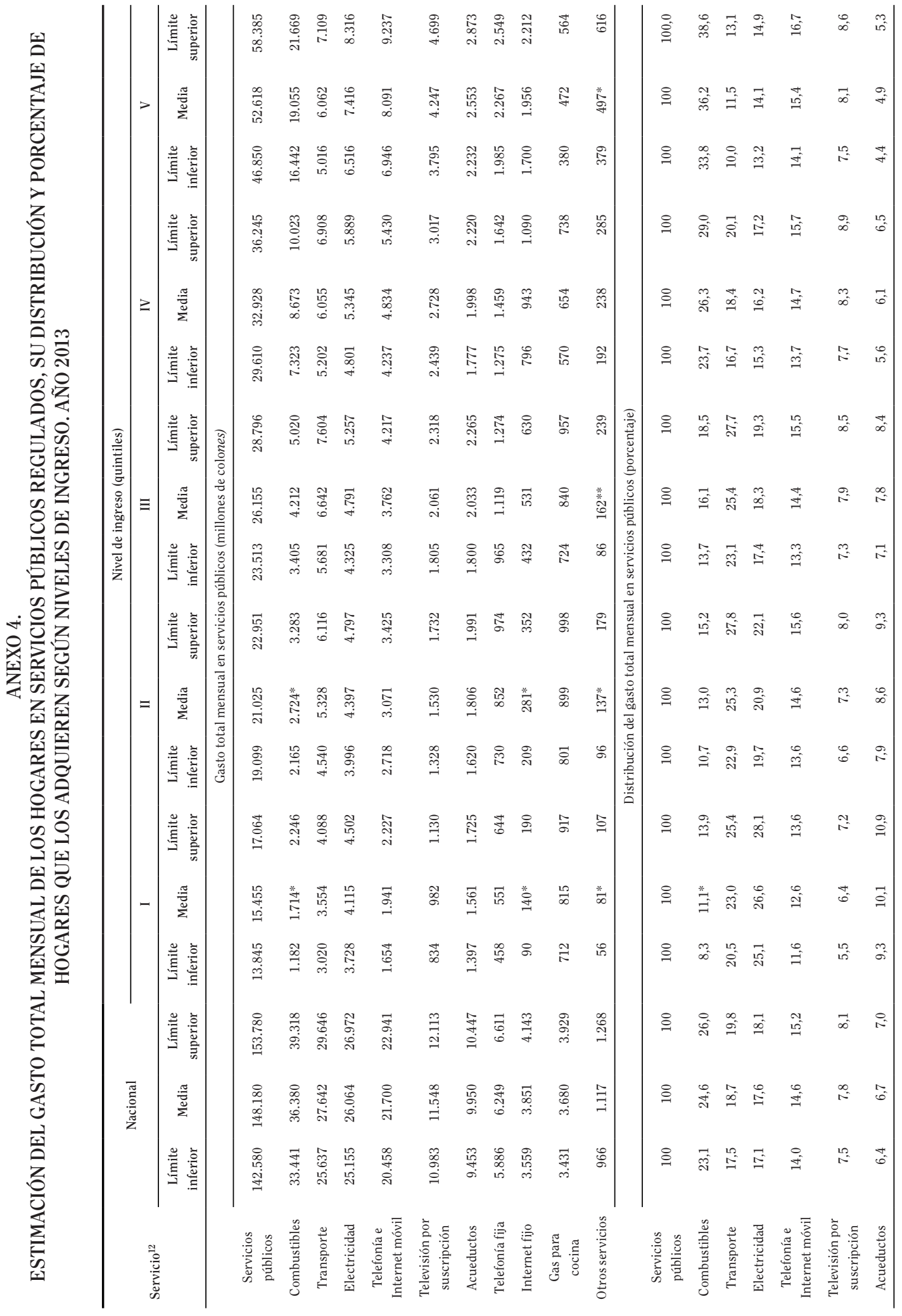




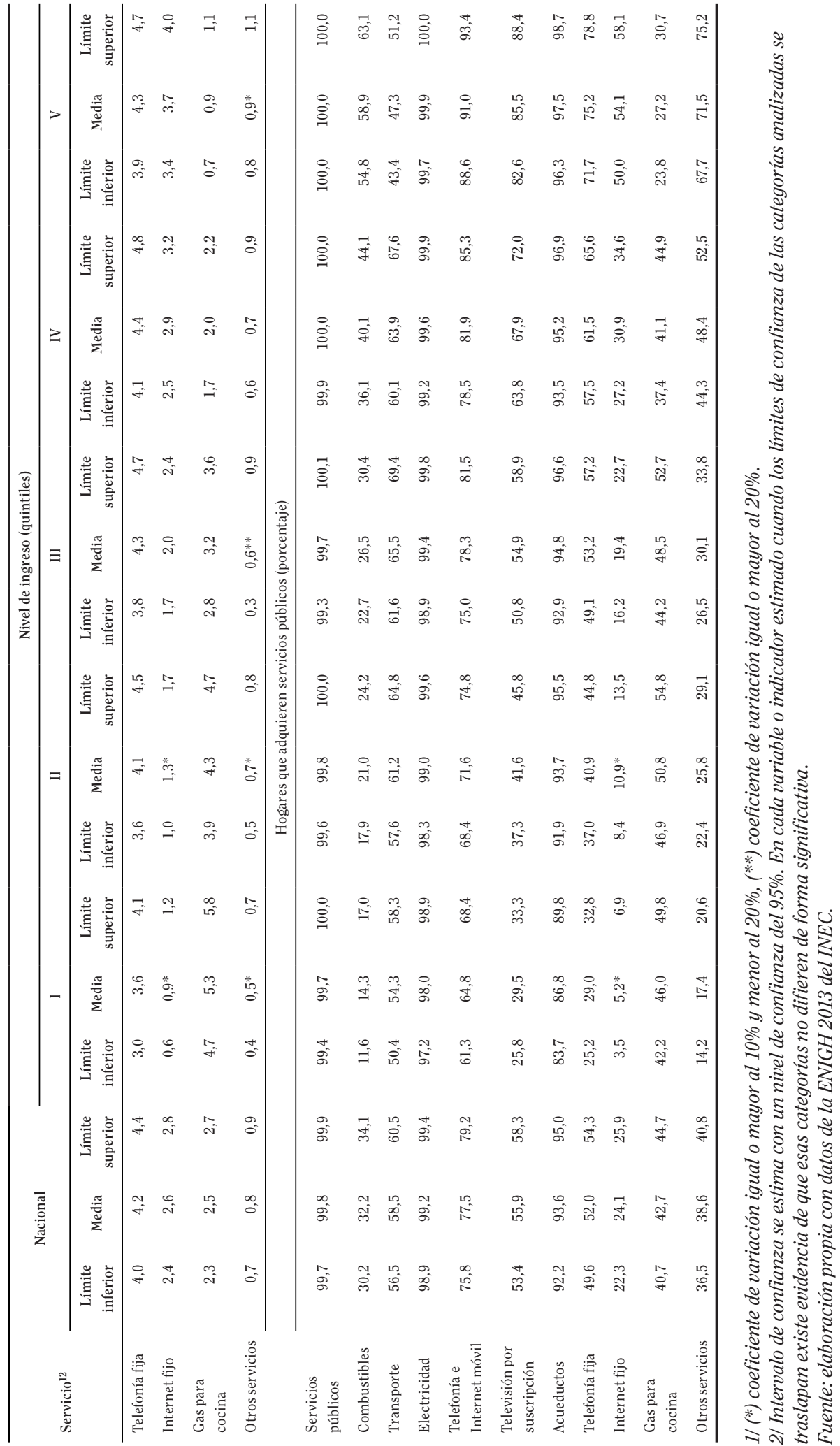




\section{ANEXO 5. \\ ESTIMACIÓN DEL INGRESO Y GASTO MENSUAL PROMEDIO DE LOS HOGARES EN SERVICIOS PÚBLICOS REGULADOS Y SU RELACIÓN, SEGÚN ZONA, REGIÓN DE PLANIFICACIÓN Y NIVEL DE INGRESO. AÑO 2013}

\begin{tabular}{|c|c|c|c|c|c|c|c|c|c|}
\hline \multirow{2}{*}{ Detalle ${ }^{1,2}$} & \multicolumn{3}{|c|}{ Ingreso promedio ${ }^{3}$} & \multicolumn{3}{|c|}{$\begin{array}{c}\text { Gasto promedio en servicios } \\
\text { públicos }\end{array}$} & \multicolumn{3}{|c|}{$\begin{array}{l}\text { Relación entre el gasto en } \\
\text { servicios públicos e ingresos }\end{array}$} \\
\hline & $\begin{array}{l}\text { Límite } \\
\text { inferior }\end{array}$ & Media & $\begin{array}{r}\text { Límite } \\
\text { superior }\end{array}$ & $\begin{array}{l}\text { Límite } \\
\text { inferior }\end{array}$ & Media & $\begin{array}{r}\text { Límite } \\
\text { superior }\end{array}$ & $\begin{array}{l}\text { Límite } \\
\text { inferior }\end{array}$ & Media & $\begin{array}{r}\text { Límite } \\
\text { superior }\end{array}$ \\
\hline & \multicolumn{3}{|c|}{ Colones corrientes } & \multicolumn{3}{|c|}{ Colones corrientes } & \multicolumn{3}{|l|}{ Porcentaje } \\
\hline Nacional & 740.772 & 792.025 & 843.277 & 102.059 & 106.267 & 110.475 & 12,8 & 13,4 & 14,0 \\
\hline \multicolumn{10}{|l|}{ Zona } \\
\hline Urbano & 836.990 & 908.721 & 980.452 & 110.524 & 116.254 & 121.983 & 12,1 & 12,8 & 13,5 \\
\hline Rural & 440.190 & 472.539 & 504.887 & 74.362 & 78.856 & 83.350 & 15,9 & 16,6 & 17,3 \\
\hline \multicolumn{10}{|l|}{$\begin{array}{l}\text { Región de } \\
\text { planificación }\end{array}$} \\
\hline Central & 850.962 & 934.661 & 1.018 .360 & 112.154 & 118.870 & 125.587 & 12,0 & 12,7 & 13,5 \\
\hline Chorotega & 495.882 & 550.458 & 605.034 & 82.192 & 89.205 & 96.218 & 15,2 & 16,1 & 17,1 \\
\hline Pacífico Central & 519.030 & 601.642 & 684.254 & 88.980 & 96.558 & 104.136 & 14,4 & 16,0 & 17,6 \\
\hline Brunca & 468.652 & 520.595 & 572.539 & 73.953 & 80.275 & 86.598 & 14,2 & 15,4 & 16,6 \\
\hline Huertar Caribe & 474.490 & 533.727 & 592.963 & 73.191 & 81.765 & 90.338 & 14,2 & 15,3 & 16,3 \\
\hline Huetar Norte & 491.637 & 553.019 & 614.401 & 73.108 & 79.194 & 85.280 & 13,2 & 14,2 & 15,3 \\
\hline \multicolumn{10}{|l|}{$\begin{array}{l}\text { Quintil de } \\
\text { ingreso }\end{array}$} \\
\hline I & 217.348 & 225.615 & 233.882 & 52.454 & 55.560 & 58.666 & 23,3 & 24,5 & 25,8 \\
\hline II & 361.713 & 376.507 & 391.301 & 71.253 & 75.329 & 79.405 & 19,1 & 20,0 & 20,8 \\
\hline III & 527.552 & 550.096 & 572.641 & 88.979 & 93.863 & 98.746 & 16,2 & 17,0 & 17,8 \\
\hline IV & 787.354 & 821.011 & 854.668 & 111.034 & 117.904 & 124.774 & 13,7 & 14,4 & 15,0 \\
\hline V & 1.807 .068 & 1.987.355 & 2.167 .643 & 177.030 & 188.449 & 199.868 & 8,8 & 9,5 & 10,2 \\
\hline
\end{tabular}

$1 /(*)$ coeficiente de variación igual o mayor al 10\% y menor al 20\%, (**) coeficiente de variación igual o mayor al $20 \%$. 2/ Intervalo de confianza se estima con un nivel de confianza del 95\%. En cada variable o indicador estimado cuando los límites de confianza de las categorías analizadas se traslapan existe evidencia de que esas categorías no difieren de forma significativa. 3/ Corresponde al ingreso corriente neto del hogar sin valor locativo.

Fuente: elaboración propia con datos de la ENIGH 2013 del INEC. 


\begin{tabular}{|c|c|c|c|c|c|}
\hline \multirow{2}{*}{ Empresa } & \multirow{2}{*}{$\begin{array}{l}\text { Ingreso mensual } \\
\text { promedio }\end{array}$} & \multicolumn{3}{|c|}{ Gasto mensual hogares (millones de colones) } & \multirow{2}{*}{$\begin{array}{c}\text { Coeficiente } \\
\text { de variación (\%) }\end{array}$} \\
\hline & & Límite inferior & Media $^{2}$ & Límite superior & \\
\hline & \multicolumn{5}{|c|}{ Servicio de electricidad } \\
\hline Total & 25.271 & 25.155 & 26.064 & 26.972 & 1,8 \\
\hline ICE & 10.663 & 10.187 & 11.417 & 12.646 & 5,5 \\
\hline CNFL & 9.123 & 7.570 & 8.982 & 10.394 & 4,5 \\
\hline ESPH o Jasec & 2.634 & 1.971 & 2.968 & 3.965 & 8,0 \\
\hline \multirow[t]{2}{*}{ Cooperativas } & 2.852 & 2.118 & 2.680 & 3.242 & 5,1 \\
\hline & \multicolumn{5}{|c|}{ Servicio de acueductos y alcantarillados } \\
\hline AyA & 6.091 & 5.428 & 6.158 & 6.889 & 6,0 \\
\hline
\end{tabular}

1/ Se estima entre estas fechas debido a que el pago mensual en estos servicios se realiza al mes vencido, ver documento sobre ámbito temporal del documento metodológico de la ENIGH 2013.

2/ Los intervalos de confianza se estiman con un nivel de confianza del $95 \%$.

Fuente: elaboración con datos de la ENIGH 2013 del INEC y la Aresep.

Todas las estimaciones incluyen en el intervalo de confianza (95\%) el valor real de los ingresos de las empresas proveedoras del servicio por concepto de tarifa residencial. 


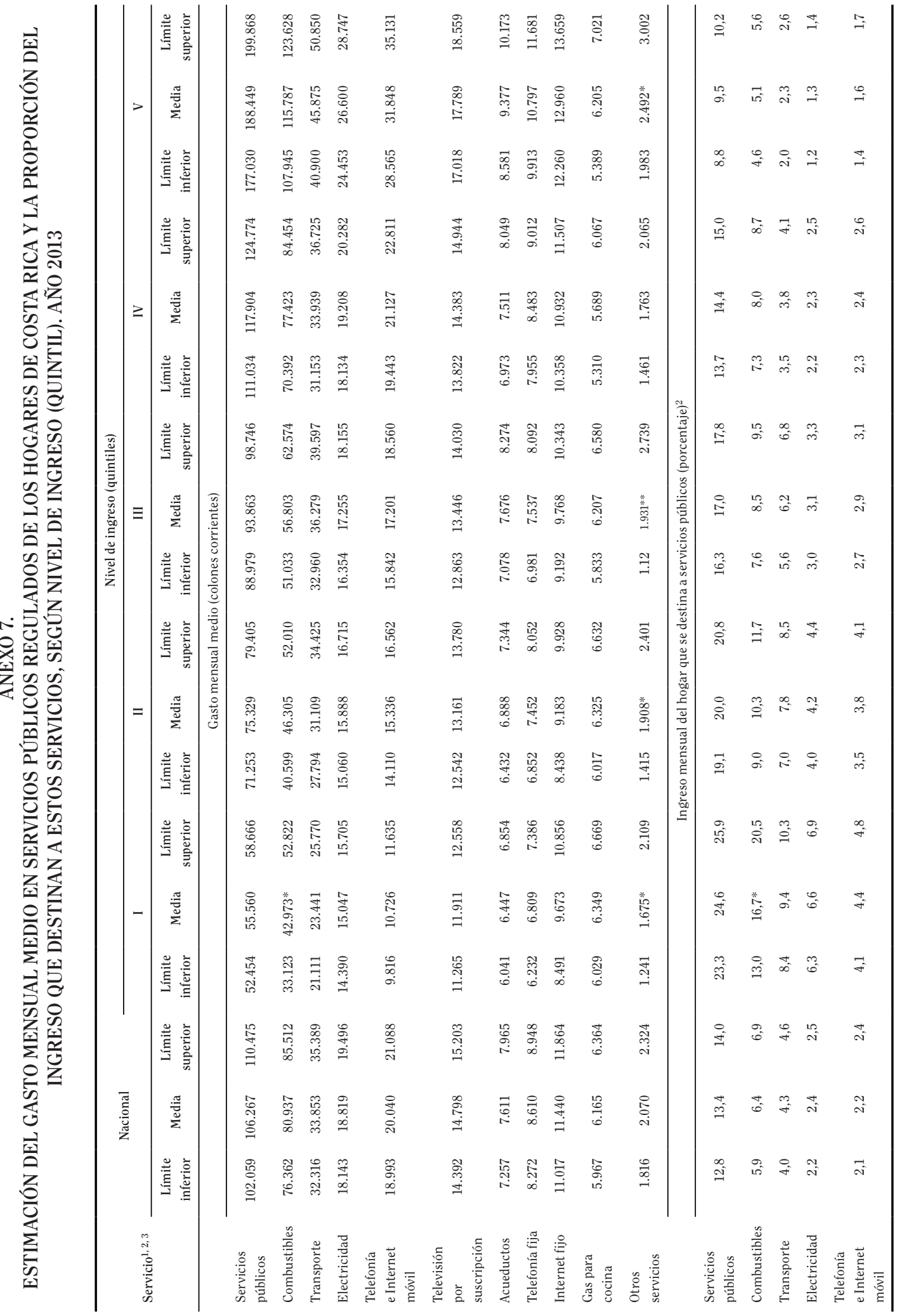




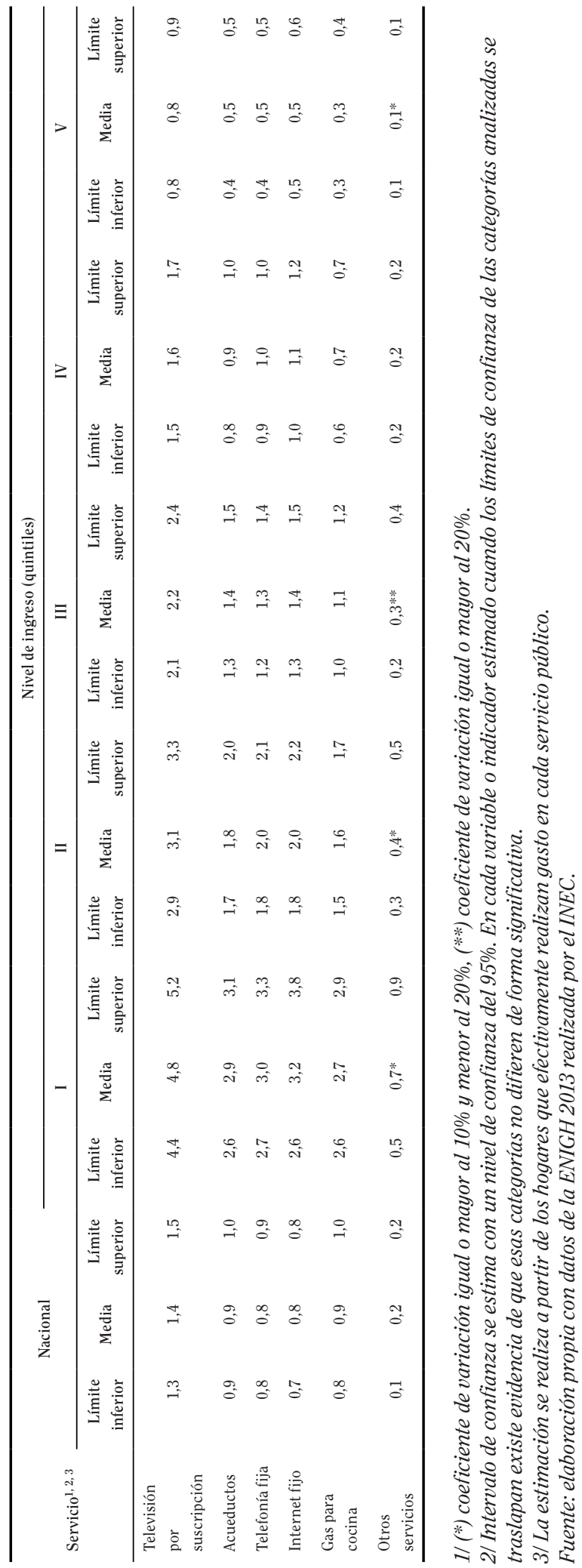




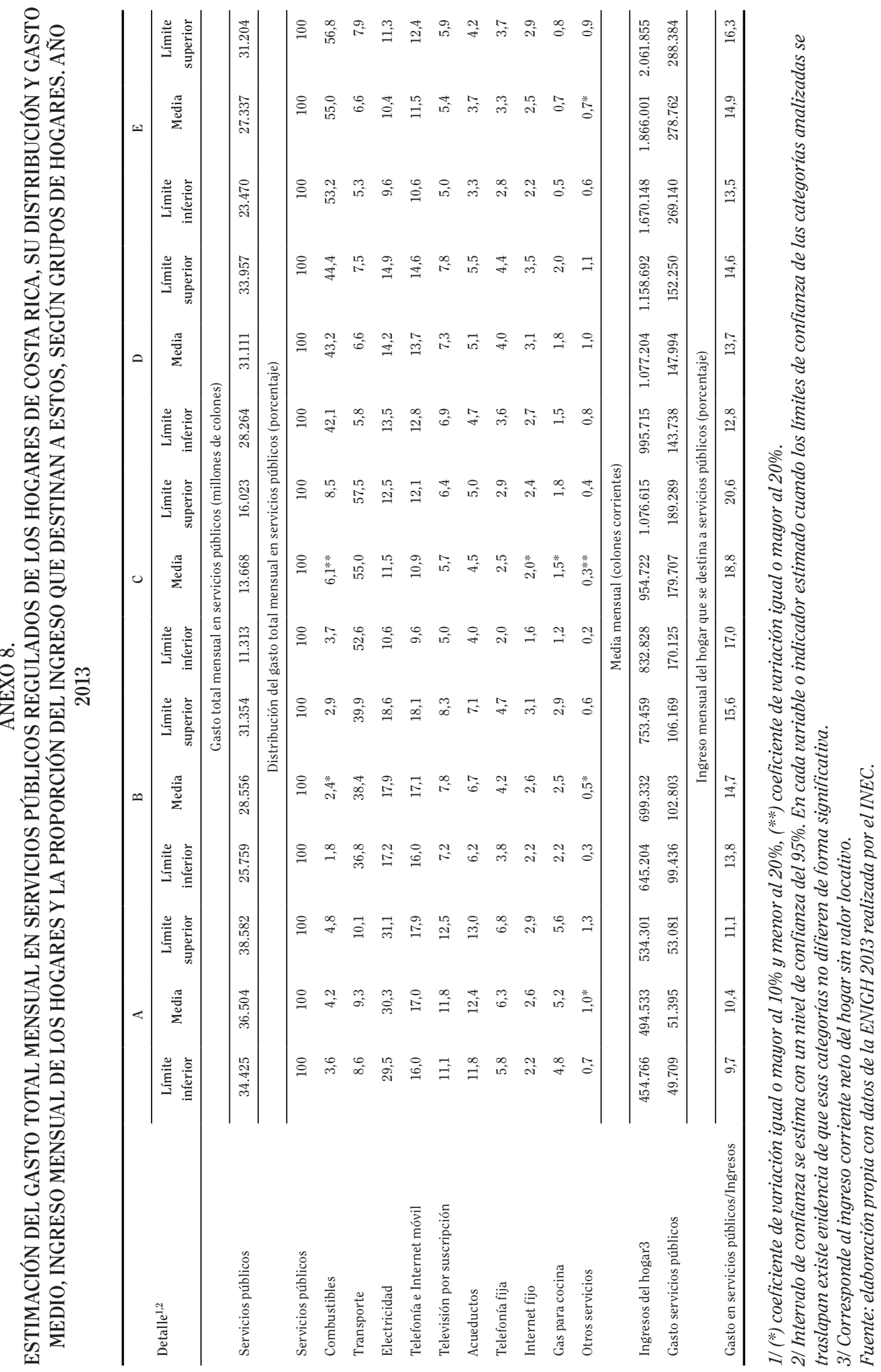




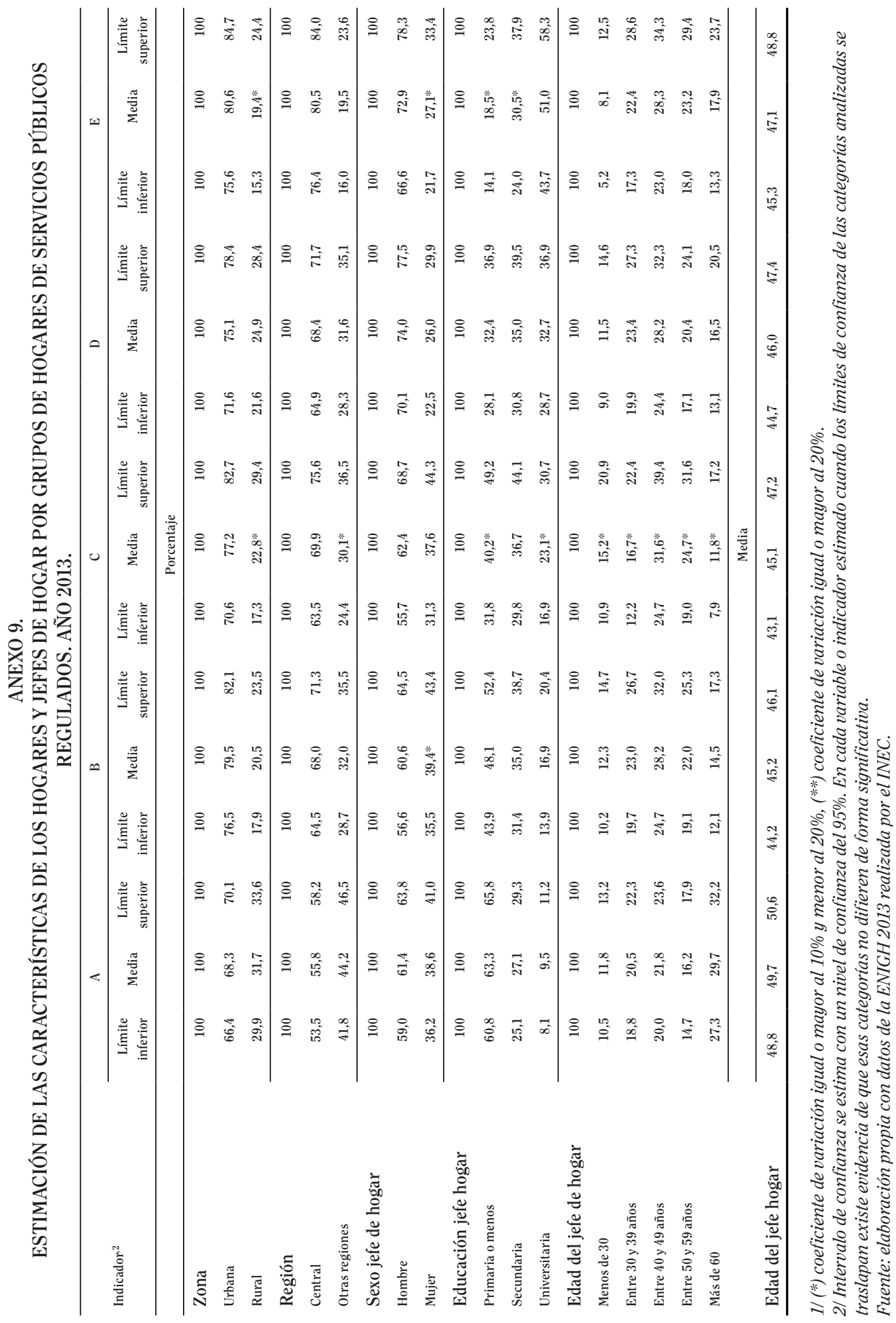




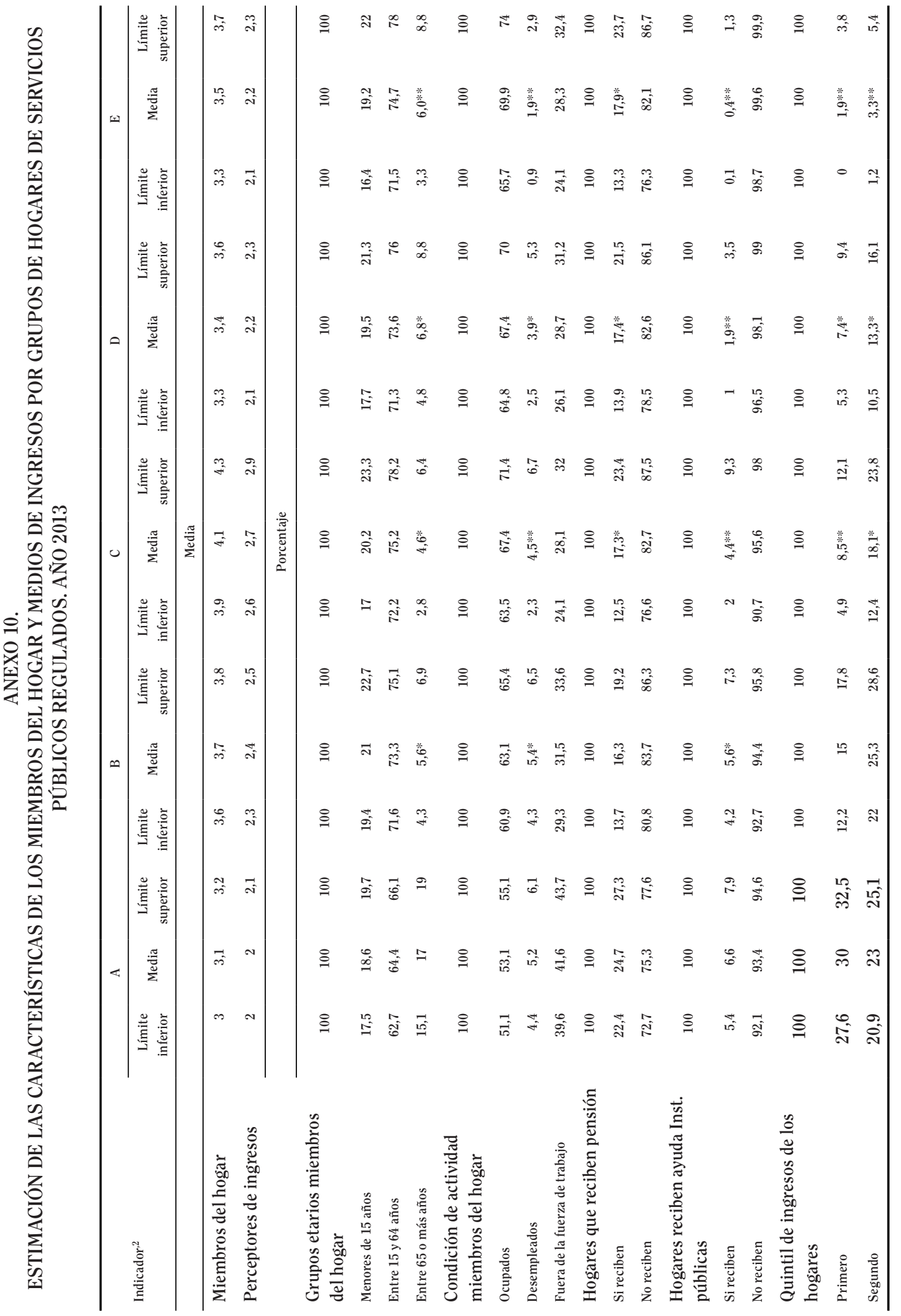




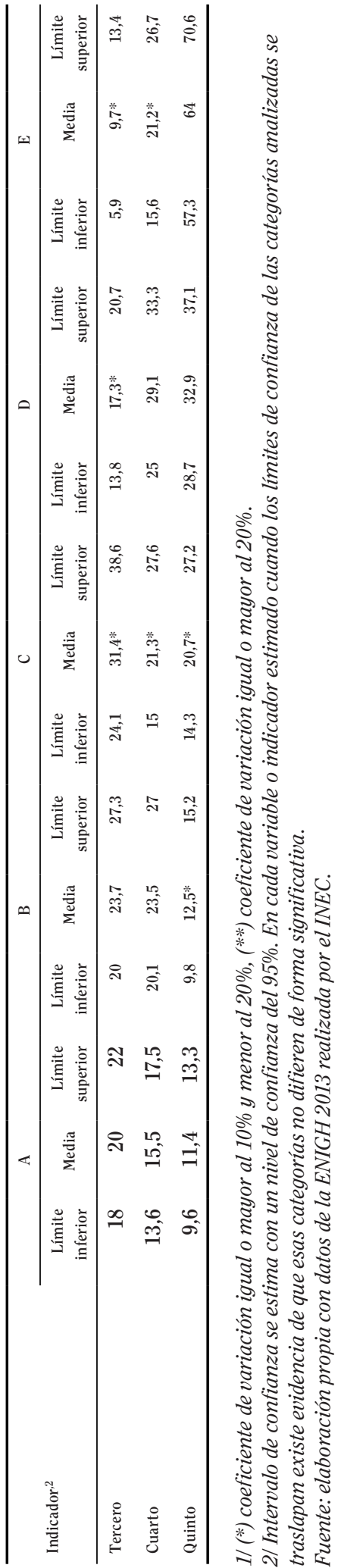

Revista de Ciencias Económicas 36-N²: julio-diciembre 2018 / 95-138 / ISSN: 0252-9521 


\section{ANEXO 11. \\ ESTIMACIÓN DEL GASTO TOTAL MENSUAL EN SERVICIOS PÚBLICOS REGULADOS DE LOS HOGARES DE COSTA RICA, SU DISTRIBUCIÓN Y GASTO MEDIO, INGRESO MENSUAL DE LOS HOGARES Y LA PROPORCIÓN DEL INGRESO QUE DESTINAN A ESTOS, SEGÚN SUBGRUPOS DE “HOGARES CON GASTO BAJO”. AÑO 2013}

\begin{tabular}{|c|c|c|c|c|c|c|c|c|c|c|c|c|}
\hline \multirow[b]{2}{*}{ Detalle $e^{1,2}$} & \multicolumn{3}{|c|}{$\mathrm{A}$} & \multicolumn{3}{|c|}{$\mathrm{A} 1$} & \multicolumn{3}{|c|}{ A2 } & \multicolumn{3}{|c|}{ A3 } \\
\hline & $\begin{array}{l}\text { Límite } \\
\text { inferior }\end{array}$ & Media & $\begin{array}{l}\text { Límite } \\
\text { superior }\end{array}$ & $\begin{array}{l}\text { Límite } \\
\text { inferior }\end{array}$ & Media & $\begin{array}{l}\text { Límite } \\
\text { superior }\end{array}$ & $\begin{array}{l}\text { Límite } \\
\text { inferior }\end{array}$ & Media & $\begin{array}{l}\text { Límite } \\
\text { superior }\end{array}$ & $\begin{array}{l}\text { Límite } \\
\text { inferior }\end{array}$ & Media & $\begin{array}{r}\text { Límite } \\
\text { superior }\end{array}$ \\
\hline \multirow{3}{*}{$\begin{array}{l}\text { Servicios } \\
\text { públicos }\end{array}$} & \multicolumn{12}{|c|}{ Gastos totales (millones de colones) } \\
\hline & 34.425 & 36.504 & 38.582 & 14.789 & 16.160 & 17.532 & 6.556 & 7.632 & 8.709 & 11.205 & 12.711 & 14.217 \\
\hline & \multicolumn{12}{|c|}{ Distribución del gasto total (porcentaje) } \\
\hline $\begin{array}{l}\text { Servicios } \\
\text { públicos }\end{array}$ & 100 & 100 & 100 & 100 & 100 & 100 & 100 & 100 & 100 & 100 & 100 & 100 \\
\hline Combustibles & 3,6 & 4,2 & 4,8 & 3,4 & $4,4^{*}$ & 5,4 & 3,9 & $5,2^{*}$ & 6,5 & 2,4 & $3,3^{*}$ & 4,3 \\
\hline Transporte & 8,6 & 9,3 & 10,1 & 10,8 & 11,8 & 12,8 & 9 & 10,3 & 11,6 & 4,6 & 5,6 & 6,5 \\
\hline Electricidad & 29,5 & 30,3 & 31,1 & 32,1 & 33,2 & 34,2 & 26,1 & 27,5 & 28,9 & 26,9 & 28,2 & 29,6 \\
\hline $\begin{array}{l}\text { Telefonía e } \\
\text { Internet móvil }\end{array}$ & 16 & 17 & 17,9 & 13,7 & 14,8 & 15,8 & 14,9 & 16,7 & 18,5 & 17,9 & 19,9 & 21,9 \\
\hline $\begin{array}{l}\text { Televisión por } \\
\text { suscripción }\end{array}$ & 11,1 & 11,8 & 12,5 & 7,8 & 8,7 & 9,7 & 11,1 & 12,2 & 13,4 & 14,2 & 15,4 & 16,5 \\
\hline Acueductos & 11,8 & 12,4 & 13 & 12,5 & 13,4 & 14,3 & 11,6 & 12,8 & 14 & 9,9 & 10,8 & 11,7 \\
\hline Telefonía fija & 5,8 & 6,3 & 6,8 & 4,5 & 5,1 & 5,7 & 5,4 & 6,2 & 7,1 & 7,1 & 7,9 & 8,7 \\
\hline Internet fijo & 2,2 & 2,6 & 2,9 & 0,7 & $1,0^{*}$ & 1,4 & 1,7 & $2,5^{*}$ & 3,2 & 3,9 & 4,6 & 5,4 \\
\hline $\begin{array}{l}\text { Gas para } \\
\text { cocina }\end{array}$ & 4,8 & 5,2 & 5,6 & 6,4 & 6,9 & 7,5 & 4,7 & 5,5 & 6,4 & 2,4 & 2,8 & 3,2 \\
\hline \multirow[t]{2}{*}{$\begin{array}{l}\text { Otros } \\
\text { servicios }\end{array}$} & $0,7^{*}$ & 1 & 1,3 & 0,4 & $0,7^{*}$ & 0,9 & 0,1 & $1,1^{* *}$ & 2 & 1 & $1,4^{*}$ & 1,9 \\
\hline & \multicolumn{12}{|c|}{ Ingreso y gasto medio (colones corrientes) } \\
\hline $\begin{array}{l}\text { Ingresos del } \\
\text { hogar3 }\end{array}$ & 454.766 & 494.533 & 534.301 & 252.102 & 261.760 & 271.418 & 427.937 & 451.461 & 474.984 & 861.072 & 984.489 & 1.107 .907 \\
\hline \multirow[t]{2}{*}{$\begin{array}{l}\text { Gasto } \\
\text { servicios } \\
\text { públicos }\end{array}$} & 49.709 & 51.395 & 53.081 & 41.392 & 42.915 & 44.439 & 50.277 & 53.643 & 57.009 & 61.994 & 66.407 & 70.820 \\
\hline & \multicolumn{12}{|c|}{ Ingresos destinados al consumo en servicios públicos (porcentaje) } \\
\hline $\begin{array}{l}\text { Gasto en } \\
\text { servicios } \\
\text { públicos/ } \\
\text { Ingresos }\end{array}$ & 9,7 & 10,4 & 11,1 & 15,9 & 16,4 & 16,9 & 11,3 & 11,9 & 12,6 & 6,1 & 6,7 & 7,4 \\
\hline
\end{tabular}

$1 /(*)$ coeficiente de variación igual o mayor al 10\% y menor al 20\%, (**) coeficiente de variación igual o mayor al $20 \%$. $2 /$ Intervalo de confianza se estima con un nivel de confianza del $95 \%$. En cada variable o indicador estimado cuando los límites de confianza de las categorías analizadas se traslapan existe evidencia de que esas categorías no difieren de forma significativa.

$3 /$ Corresponde al ingreso corriente neto del hogar sin valor locativo.

Fuente: elaboración propia con datos de la ENIGH 2013 realizada por el INEC. 
ANEXO 12.

RESULTADO DEL ANÁLISIS DEL MÉTODO DEL CODO PARA SELECCIONAR NÚMERO ÓPTIMO DE GRUPOS

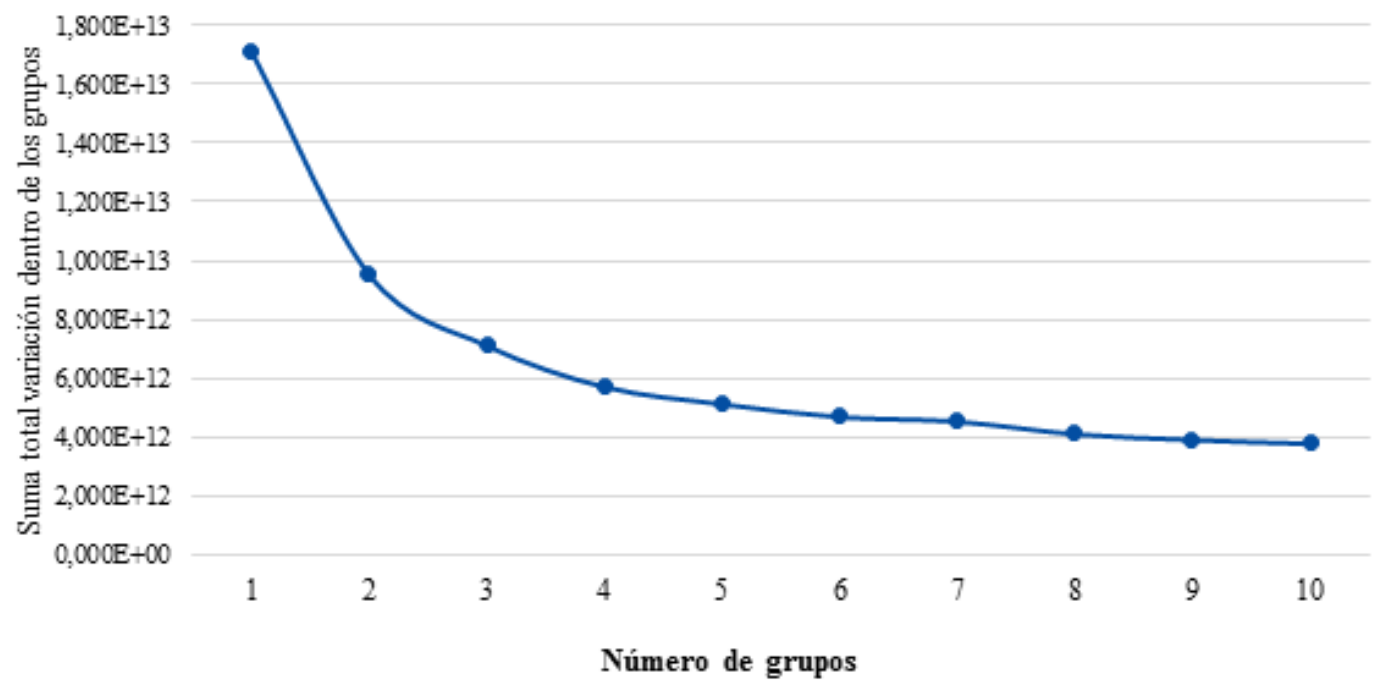

Fuente: elaboración propia con datos de la ENIGH 2013 del INEC. 